\title{
Early detection of developmental delays in vulnerable children by community care workers using an mHealth tool
}

by

Maria $\mathrm{N}$ van der Merwe

(12062482)

Dissertation submitted in fulfillment of the requirements for the degree MA (Speech-Language Pathology) in the Department of Speech-Language Pathology and Audiology at the UNIVERSITY OF PRETORIA

FACULTY OF HUMANITIES

Supervisor: Dr Jeannie van der Linde

Co-supervisors: Miss Renata Mosca, Prof De Wet Swanepoel

October 2017 
The Department of Speech-Language Pathology and Audiology places great emphasis upon integrity and ethical conduct in the preparation of all written work submitted for academic evaluation.

While academic staff teach you about referencing techniques and how to avoid plagiarism, you too have a responsibility in this regard. If you are at any stage uncertain as to what is required, you should speak to your lecturer before any written work is submitted.

You are guilty of plagiarism if you copy something from another author's work (eg a book, an article or a website) without acknowledging the source and pass it off as your own. In effect you are stealing something that belongs to someone else. This is not only the case when you copy work word-for-word (verbatim), but also when you submit someone else's work in a slightly altered form (paraphrase) or use a line of argument without acknowledging it. You are not allowed to use work previously produced by another student. You are also not allowed to let anybody copy your work with the intention of passing if off as his/her work.

Students who commit plagiarism will not be given any credit for plagiarised work. The matter may also be referred to the Disciplinary Committee (Students) for a ruling. Plagiarism is regarded as a serious contravention of the University's rules and can lead to expulsion from the University.

The declaration which follows must accompany all written work submitted while you are a student of the Department of Speech-Language Pathology and Audiology. No written work will be accepted unless the declaration has been completed and attached.

Full names of student: Maria Neethling van der Merwe

Student number: 12062482

Topic of work: $\quad$ Early detection of developmental delays in vulnerable children by community care workers using an mHealth tool.

\section{Declaration}

1. I understand what plagiarism is and am aware of the University's policy in this regard.

2. I declare that this dissertation is my own original work. Where other people's work has been used (either from a printed source, Internet or any other source), this has been properly acknowledged and referenced in accordance with departmental requirements.

3. I have not used work previously produced by another student or any other person to hand in as my own.

4. I have not allowed, and will not allow, anyone to copy my work with the intention of passing it off as his or her own work.

\section{SIGNATURE}

DATE 


\section{ACKNOWLEDGEMENTS}

Psalm 46:5

First and foremost, all the glory to my Heavenly Father for blessing me with the strength and diligence to complete this very big task. Lord, You gave me this dream in a time of such uncertainty. Thank You for the courage to push on through the hard times...

Dr van der Linde, Miss Mosca and Prof Swanepoel, it has been an honour to work with such a kind hearted, brilliant group of supervisors! Thank you for all your guidance and support, for sharing your knowledge with me and for keeping me humble throughout this journey. Thank you for always challenging me to reach my full potential. I look forward to many more opportunities to work with you and to learn from you and your seemingly endless well of knowledge!

Jeannie, thank you for not only being my supervisor, but also for being a dear friend and sister in Christ. Thank you for helping me stay grounded and thank you for always praying with me and for me! I cannot even name half the things you have done for me this year... You are truly my role model! Thank you.

My friends and family, you know who you are... Thank you for all the support, encouragement and coffee breaks when I needed it most. You definitely made this task seem less daunting and you always made sure that I still had a smile on my face, no matter how little sleep l've had. I am forever grateful. 


\section{TABLE OF CONTENTS}

TABLES

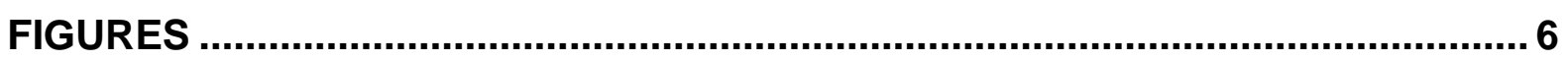

LIST OF ABBREVIATIONS .......................................................................

ABSTRACT

1. INTRODUCTION

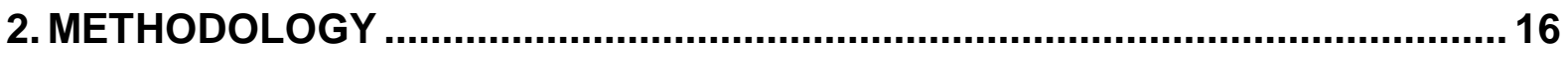

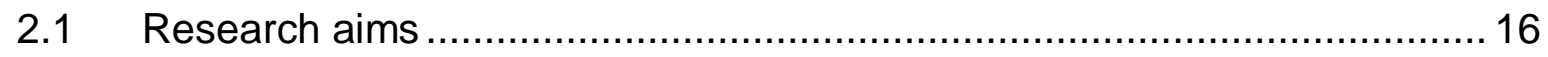

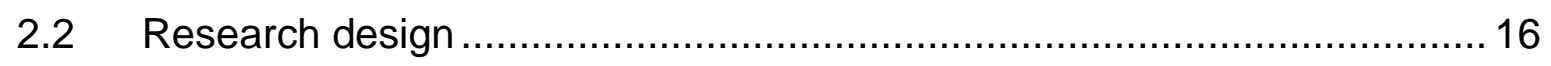

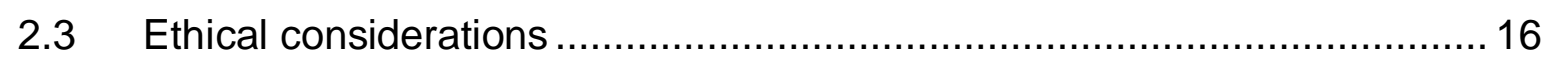

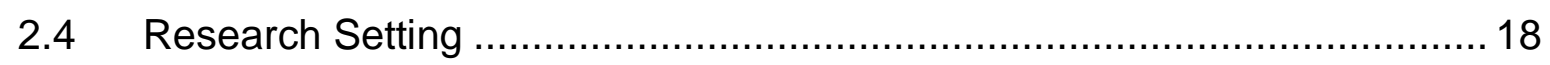

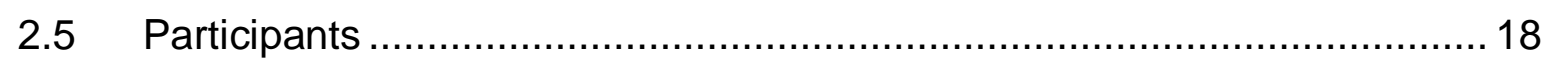

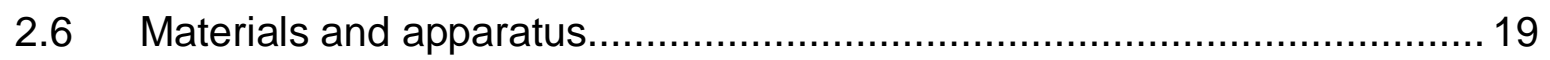

$2.7 \quad$ Procedures for data collection.......................................................... 21

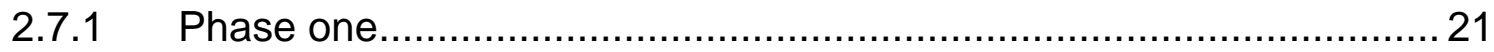

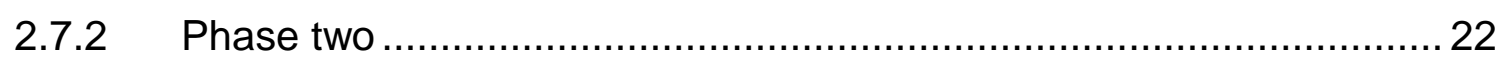

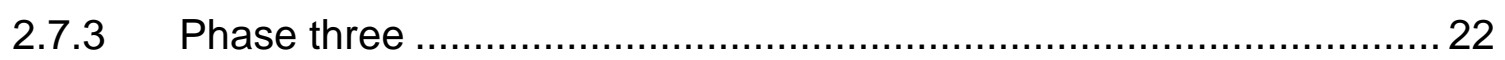

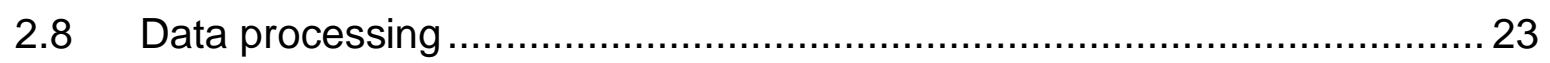

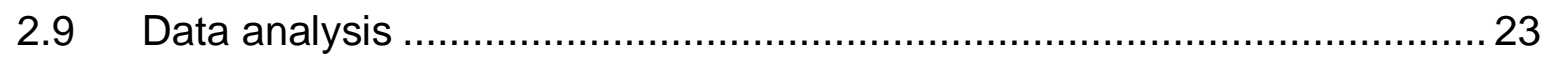

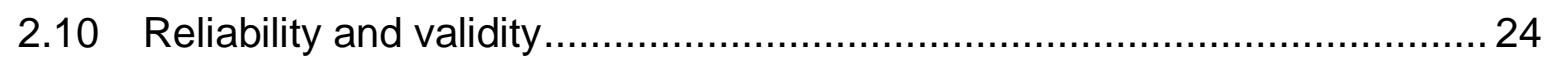

3. EARLY DETECTION OF DEVELOPMENTAL DELAYS IN VULNERABLE CHILDREN BY COMMUNITY HEALTH WORKERS USING AN MHEALTH TOOL 25

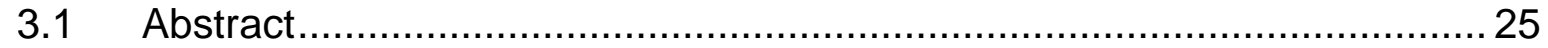

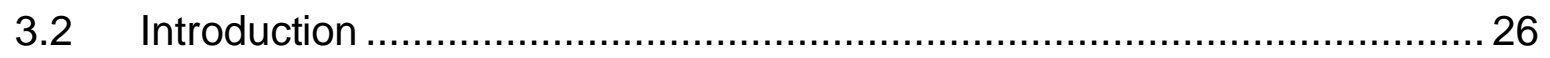

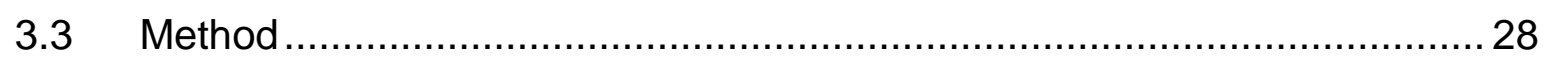

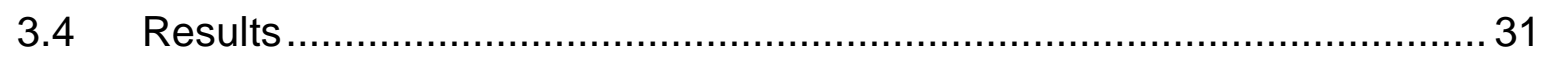

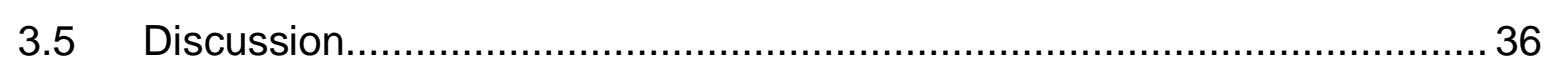

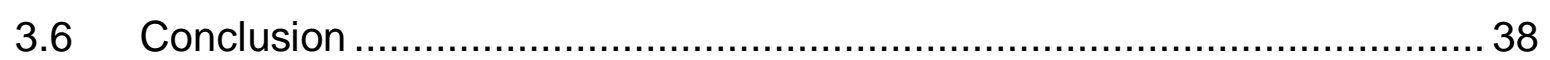

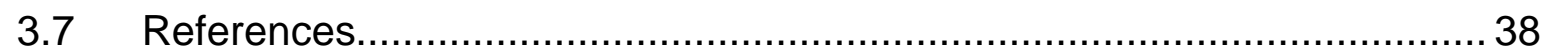

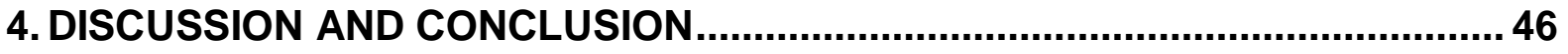

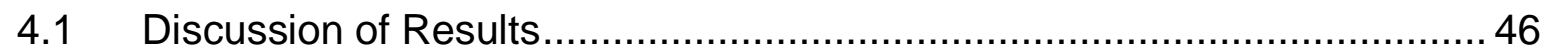

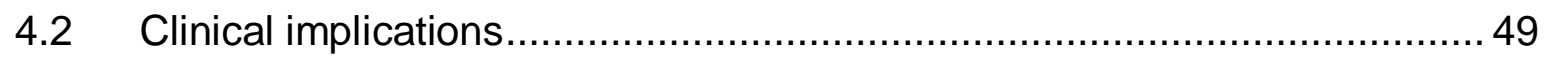

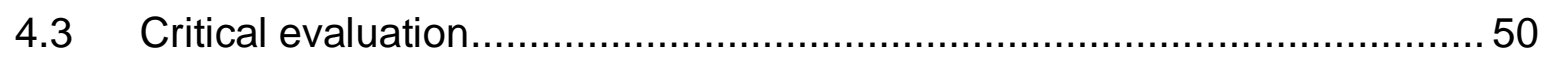

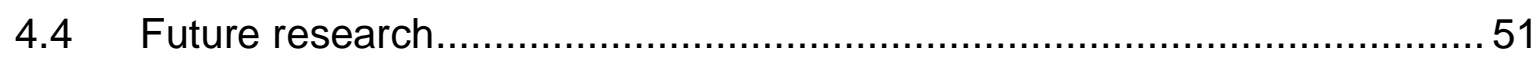

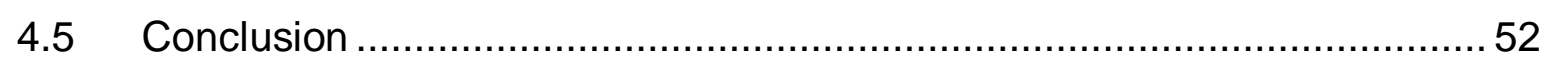

5. REFERENCES 
6. APPENDICES

APPENDIX A: ETHICAL CLEARANCE: FACULTY OF HUMANITIES, UNIVERSITY OF PRETORIA 65

APPENDIX B: REQUEST FOR COLLABORATION WITH FUTURE FAMILIES .. 67 APPENDIX C: PARENT/CAREGIVER INFORMATION LEAFLET AND INFORMED CONSENT FORM. 71

APPENDIX D: COMMUNITY CARE WORKER INFORMATION LEAFLET AND INFORMED CONSENT FORM. 75 APPENDIX E: CAREGIVER BACKGROUND INFORMATION QUESTIONNAIRE 79

APPENDIX F: COMMUNITY CARE WORKER QUESTIONNAIRE 83 


\section{TABLES}

Table 1: Demographic information of participants

Table 2: Overall referral rate across PEDS tools, PEDS:DM and PEDS and two age groups

Table 3: Referral rates across age categories

Table 4: CCWs' perceptions regarding value of an mHealth screening programme

Table 5: Thematic analysis of CCWs' comments regarding screening programme 


\section{FIGURES}

Figure 1: Evidence-based pathways of the PEDS

Figure 2: Phases of the implementation of the screening programme

Figure 3: Stages of the screen and rescreen process facilitated by CCWs 


\section{LIST OF ABBREVIATIONS}

$\begin{array}{lll}\text { CCWs } & - & \text { Community care workers } \\ \text { CHWs } & - & \text { Community health workers } \\ \text { COPC } & - & \text { Community oriented primary care } \\ \text { eHealth } & - & \text { electronic Health } \\ \text { LMIC } & - & \text { Low- and middle-income countries } \\ \text { mHealth } & - & \text { mobile Health } \\ \text { NGOs } & - & \text { Non-governmental organizations } \\ \text { PEDS } & - & \text { Parents' Evaluation of Developmental Status } \\ & & \text { (Glascoe, 2013) } \\ \text { PEDS: DM } & - & \text { Parents' Evaluation of Developmental Status - Developmental } \\ & & \text { Milestones (Brothers, Glascoe, \& Robertshaw, 2008) } \\ \text { PHC } & - & \text { Primary health care } \\ \text { RTHB } & - & \text { Road to Health Booklet } \\ \text { SES } & - & \text { Socio-economic status } \\ \text { SLT } & - & \text { Speech-language therapist } \\ \text { SMS } & - & \text { Short message service } \\ \text { SPSS } & - & \text { Statistic Package Social Sciences } \\ \end{array}$

\section{FORMATTING}

APA referencing style was utilised in this dissertation. 


\section{ABSTRACT}

Developmental delays are increasing worldwide, as a result of exposure to environmental risk factors, such as poverty. Early detection services are often inaccessible in low- and middle-income countries (LMIC) due to limited human resources and a lack of knowledge regarding development. This study investigated an mHealth screening programme with community care workers (CCWs) facilitating early detection of developmental delays in children from underserved communities. An exploratory research design that was both qualitative and quantitative in nature was applied. CCWs, employed by a community-based non-governmental organisation (NGO), were trained to administer the Parents' Evaluation of Developmental Status (PEDS) smartphone application as part of home-based services offered to families affected by HIV/AIDS. After the training, they screened 138 children (mean=19.2 months, $S D=11.1$ ) in the community. Children who failed the screen were rescreened, and depending the outcome, were referred for diagnostic assessment. CCWs completed a questionnaire regarding their perceptions and experiences of communitybased mHealth-assisted screening. The results indicated an overall referral rate of $69 \%$. Older children (19-38 months old) had a significantly higher $(p<0.05$; ChiSquare) referral rate $(57 \% ; n=39)$ compared to those aged $0-18$ months $(40 \% ; n=24)$. The high referral rate may be attributed to the at-risk population sampled. Average screening time was 12.5 minutes and on average ten children were screened per day. CCWs perceived mHealth screening as valuable in terms of utility, outcomes and contribution to developmental knowledge for community members and CCWs. Community-based services are a promising platform for the implementation of mHealth-assisted early developmental screening programmes for improved access to early detection and surveillance for vulnerable children and their families. CCWs indicated that they were motivated to promote increased developmental surveillance in their community.

Keywords: Development, screening, community health workers, mHealth 


\title{
1. INTRODUCTION
}

\author{
Chapter aim: The chapter provides background regarding current primary \\ healthcare service delivery in South Africa. The rationale for new or \\ alternative methods of service delivery is explored. An argument is \\ formulated for the use of mHealth developmental screening by CCWs as a \\ service delivery model in the underserved South African context.
}

A $17 \%$ global increase in developmental delays or disorders has been reported and represents 1.8 million more children with developmental delays than a decade earlier (Boyle et al., 2011). In South Africa, more than a third (34\%) of the total population are children (Delany, Jehoma, \& Lake, 2016) and 64\% of children live in poverty (Kyarkanaye, Dada, \& Samuels, 2017). Poverty, and exposure to other environmental and biological risk factors, increase the risk for developmental delays. These include, amongst others, poor antenatal care, malnutrition, inadequate sanitation and exposure to HIV/AIDS (Samuels, Slemming, \& Balton, 2012). Risk factors may lead to frequent hospitalisation which directly impacts development (Kelly, Sacker, Schoon, \& Nazroo, 2006). Poverty negatively affects social welfare as well as academic achievement, health and general wellbeing. In turn, risk factors may destabilise future educational success (Kyarkanaye et al., 2017). The impact of these factors often result in a highrisk and vulnerable population (van der Linde et al., 2016). The effects of poverty on child development is a well-documented topic that has received renewed attention locally and internationally due to the increase and developmental impact (Kyarkanaye et al., 2017).

Despite many efforts by the South African government to make healthcare services accessible to vulnerable populations, no structured, consistent service delivery policy for developmental screening and surveillance has been established for young children in South Africa (Donald, Hall, \& Dawes, 2012). Currently, South Africa prioritises primary prevention of HIV/AIDS and tuberculosis, rather than decreasing the already present risk factors and their cascading effects on development (Barron \& Padarath, 2017). This hinders the improvement of early detection and follow-up of developmental delays and disorders.

Developmental screening tools that aid in identification, evaluation, and intervention planning should be used to respond to the challenges faced in primary healthcare 
(PHC) settings to service the needs of vulnerable communities (Maleka, van der Linde, Glascoe, \& Swanepoel, 2016). Screening refers to the process of administering a brief standardised tool to identify children at risk for possible developmental delays who require further assessment (Lipkin, 2009). Routine developmental screening is essential for developmental surveillance to take place (Schonwald, Huntington, Chan, Risko, \& Bridgemohan, 2009). Developmental surveillance represents a "longitudinal, continuous, and cumulative process" (Smith, 2016) and plays a vital role in successful and regular follow-up of children at risk for developmental delays. The Road to Health Booklet (RTHB) is a national developmental screening checklist that has been implemented by the South African Department of Health. However, this tool has not been validated and its accuracy is yet to be established (van der Linde, Swanepoel, Glascoe, Louw, \& Vinck, 2015). A recent study compared the RTHB to a recognised developmental screening tool. The use of the RTHB in public settings was found to be limited due to the lack of an established referral system. The current referral framework is insufficient as no clear guidelines exist to make informed decisions regarding referral (van der Linde, Swanepoel, Glascoe, Louw, \& Vinck, 2015). Furthermore, another study reported that $48 \%$ of nurses and other PHC personnel perceived the RTHB as abstruse (Cloete et al., 2013). The RTHB failed to identify the majority of infants at risk of a developmental delay due to its low sensitivity as developmental domains are not evaluated consistently across all age ranges (van der Linde, Swanepoel, Glascoe, Louw, \& Vinck, 2015).

Results from a recent report evaluating the expected quality of $\mathrm{PHC}$ services and care in South Africa, found that only $28 \%$ of the targeted clinics performed above average (Hunter et al., 2017). Furthermore, only $40 \%$ of all PHC facilities, which are the entry level to service delivery in South Africa (Health Systems Trust, 2012), have trained nurses (Cullinan, 2006). PHC staff, which comprises mostly of qualified nurses, auxiliary nurses and nursing students (South African Nursing Council, 2017), usually conduct developmental screening (Maleka et al., 2016). Nurses, in both urban and rural settings, are often overburdened by their caseloads. This results in less comprehensive hands-on care available to children in a given time (Donald et al., 2012). Additionally, PHC staff regularly lack knowledge and human resources to correctly identify and refer infants and toddlers with developmental delays (van der Linde, Kritzinger, \& Redelinghuys, 2009). A study reported that almost half (45\%) of 
nurses in the Western Cape felt that they had inadequate knowledge regarding typical child development in order to screen children for possible delays (Cloete et al., 2013). This can be ascribed to, amongst others, unestablished professional roles and limited knowledge regarding the scope of practice of different allied healthcare professionals. A study reporting on the working environment of $\mathrm{PHC}$ personnel concluded that $58 \%$ of participants reported not having the necessary implements to deliver adequate health services (Awases, Bezuidenhout, \& Roos, 2013). Furthermore, due to a shortage of medical professionals, PHC personnel regularly work beyond their scope of practice (Awases et al., 2013; Delobelle et al., 2011). As a result, timely identification and referral may be hampered (van der Linde et al., 2009).

Developmental screening is essential to timeously identify developmental delays in vulnerable populations, yet, these services are often difficult to access in PHC and community-based contexts. Inaccessibility is largely due to the location of the services, the costs involved in travelling to the different clinics, and the availability of skilled professionals rendering these services (Samuels et al., 2012).

Even if appropriate referral systems are set in place, less than a quarter of all South African PHC facilities offer therapeutic services, such as dietetics and speechlanguage therapy, due to understaffing (Health Systems Trust, 2012). Challenges faced in PHC also include long waiting times and inadequate space to render comfortable and private services (Hunter et al., 2017). Apart from the restrictions in human resources, cultural and linguistically relevant standardised developmental screening tools are also lacking (van der Merwe, Cilliers, Mare, van der Linde, \& Le Roux, 2017).

In South Africa, the need to identify alternative models of service delivery to facilitate universal access to healthcare is increasing (Coovadia, Jewkes, Barron, Sanders, \& Mclntyre, 2009). Community health workers (CHWs) potentially serve as the missing link between communities and the healthcare system, by providing culturally appropriate and direct health services and education in communities (Brownstein, Hirsch, Rosenthal, \& Rush, 2011). CHWs can also facilitate child development services such as developmental screening (Maleka et al., 2016). CHWs provide alternative access to vital healthcare services, particularly for vulnerable populations (Johnson \& Gunn, 2015). They also provide support to nurses and allied healthcare 
professionals by reducing the burden of service delivery on multidisciplinary health care systems (Brownstein et al., 2011). CHWs are increasingly envisioned as a trained and paid cadre for implementing preventative measures and are viewed as an integral part of the healthcare system (Singh \& Sachs, 2013). Several studies have reported on the improvement in access and quality of health services when services were successfully shifted from healthcare professionals to CHWs (Brownstein et al., 2011; Lehmann, van Damme, Barten, \& Sanders, 2009).

Internationally, CHWs are defined as community workers who "promote health within a community by assisting individuals to adopt healthy behaviours... who may deliver health related preventative services, such as blood pressure management and hearing screening" (U.S. Bureau of Labor Statistics, 2017). In many South African studies, they are also referred to as community care workers (CCWs) (Friedman et al., 2007; Moshabela, Sips, \& Barten, 2015; Okeyo \& Dowse, 2016; Sips et al., 2014). CCWs play an important role in the social welfare of community members, rather than only focusing on health needs (Pratt \& Mbaligontsi, 2014).

No clear distinctions between these terms (CHWs vs CCWs) exist across current literature, mainly due to tasks that are formally and informally added to their job descriptions (Olaniran et al., 2017). CCWs are expected to provide psychosocial support, ensure that children receive proper nutrition and have access to education and early childhood development centres. They also encourage community involvement to create awareness regarding HIV/AIDS (Moshabela et al., 2015), play a pivotal role in the prevention of illness and in managing minor health problems. In addition, they provide support to community members receiving medical treatment and medication (Austin-Evelyn et al., 2017). CHWs have made a great impact in reducing child malnutrition and mortality rates (Perry et al., 2016). In 2004, there were an estimated 40000 CHWs in South Africa (Schneider, Hlophe, \& van Rensburg, 2008), which had grown significantly to 63000 by 2014 (Perry et al., 2016).

The scope of practice of CHWs is widely debated, due to the ever evolving role they play in their communities (World Health Organization, 2015). Moreover, limited research exists that provides clarity regarding the process by which $\mathrm{CHWs}$ are trained, which may pose a challenge (O'Brien, Squires, Bixby, \& Larson, 2009). The majority of CHWs are employed by non-governmental organizations (NGOs) primarily due to 
limited governmental funding (Liu, Sullivan, Khan, Sachs, \& Singh, 2011). Besides funding, other challenges include inefficient filing systems, costs associated with printing paper-based tools, and the timely manual analysis of the data collected (Neupane et al., 2014). Some of these challenges can, however, be reduced through the use of mobile Health (mHealth) technology.

mHealth refers to the application of mobile technology to support the delivery of public health services and, ultimately, to make healthcare more accessible (Fortuin, Salie, Abdullahi, \& Douglas, 2016). mHealth is a component of electronic Health (eHealth), a "delivery of health services using the internet and related technologies" (Boogerd, Arts, Engelen, \& van de Belt, 2015). The use of mHealth in healthcare worldwide is rapidly expanding within the eHealth system (Free et al., 2010) and contains many advantages. These include cost reduction and an increase in efficiency and accessibility to healthcare in the long term (Catwell \& Sheikh, 2009). Furthermore, due to the wide availability of mobile phone technology (Surka et al., 2014), mHealth can improve availability of and access to healthcare services for people in varied settings (Catwell \& Sheikh, 2009).

In contrast, research indicated that many low- and middle-income countries (LMIC) may not yet have the necessary technological infrastructures in place in order to support the effective use of eHealth, more specifically mHealth (Drury, 2005). More recent literature reported on mobile technology and operating systems evolving so rapidly that applications and certain technologies may become outdated very quickly (Ben-Zeev et al., 2015). Equally challenging is that users have varying levels of familiarity with mobile technology and their applications (Ben-Zeev et al., 2015). Despite these concerns regarding the feasibility of mHealth in LMIC, evidence of its effectiveness in these countries have been reported (DeRenzi et al., 2011). For instance, a systematic review reported that LMIC countries such as India, Zambia, Uganda, Bangladesh, and Tanzania employ eHealth to screen and diagnose cancer in patients where physicians are unable to consult directly (DeRenzi et al., 2011). Furthermore, a global study conducted in 2015 reviewed cellphone ownership across 40 countries (Poushter, 2016). Authors found that $90 \%$ of all South African adults own a cell phone, of which $37 \%$ use a smartphone (Poushter, 2016). mHealth, as a mode 
of service delivery, may therefore be feasible for developmental screening in South Africa.

Supporting this notion, a recent study reported that the gap between patients and healthcare services can be bridged by trained CCWs using mHealth technology (Maleka et al., 2016). The use of CHWs for maternal, neonatal, and child health has made a positive impact in India in terms of disease prevention, healthcare education, and counselling, as well as immunisation reminders (Gopalan, Mohanty, \& Das, 2012; Tulenko et al., 2013). A South African mHealth service delivery model, namely community oriented primary care (COPC), was introduced in 2010 wherein CHWs help to alleviate the burden on healthcare professionals in underserved communities (Bam, Marcus, Hugo, \& Kinkel, 2013). However, there is limited evidence on the role of CCWs in the developmental screening of children, especially using mHealth technology. A developmental screening tool that makes use of mHealth technology, aiding in identifying developmental delays and that can be administered by CCWs, may be beneficial.

The Parents' Evaluation of Developmental Status (PEDS) (Glascoe, 2013b) and the Parents Evaluation of Developmental Status: Developmental Milestones (PEDS: DM) (Brothers et al., 2008) are parent-administered screening tools. The PEDS used together with the PEDS: DM is a viable, accurate approach to both developmental surveillance and screening (Brothers et al., 2008). The PEDS tools have recently been developed into a smartphone application (Maleka et al., 2016), which can be used successfully by trained CHWs (Maleka et al., 2016). Almost perfect agreement (99\%) between the screening outcome (administered by a $\mathrm{CHW}$ ) and the paper-based version (administered by a SLT) was found (Maleka et al., 2016). The PEDS tools have a standardised referral system already set in place. This system is based on five pathways, which either pass or refer a child based on the type and the amount of concerns raised (Glascoe, 2013a). This may increase the viability of developmental surveillance as focus can be directed towards the respective developmental domains.

CCWs play a vital role in underserved communities where healthcare services are inaccessible. The use of $\mathrm{mHealth}$ holds potential to facilitate and improve healthcare service delivery by CCWs (Agarwal, 2015). mHealth may be a viable approach to expand community-based developmental screening and surveillance. A 
developmental screening tool using mHealth technology administered by CCWs is a low-cost option for decentralised access to early detection. The role of CCWs in the early detection and follow-up of developmental delays in vulnerable children, as part of a service delivery model, should be explored.

The research question was therefore: What is the clinical utility and perceived value of an mHealth screening programme for early detection and surveillance of developmental delays conducted by CCWs? 


\section{METHODOLOGY}

Chapter aim: This chapter describes the main aim of the study and the way in which the research was conducted in reference to current literature. The research was conducted in three phases and each is discussed in this chapter.

\subsection{Research aims}

Research aim

To describe the clinical utility and perceived value of a CCW-administered mHealth screening programme for early detection of developmental delays in vulnerable populations.

\section{Objectives}

1. To describe the clinical utility of smartphone developmental screening conducted by CCWs in terms of referral rate, test duration and early detection of developmental delays.

2. To describe CCWs' perceptions regarding the value of an mHealth screening programme for early detection and follow-up of developmental delays in vulnerable populations.

\subsection{Research design}

An exploratory research design that is both qualitative and quantitative in nature was used. Exploratory research is used when research is in a preliminary stage and conclusive information arising from it is rare (Maxwell \& Satake, 2006). Quantitative data was used to describe the clinical utility of the smartphone developmental screening conducted by CCWs. Both quantitative and qualitative data were used to describe the perception of the CCWs regarding the use of an mHealth screening programme.

\subsection{Ethical considerations}

There are many ethical guidelines to consider when working with participants to ensure that the rights and welfare of all participants are protected (Maxwell \& Satake, 2006). This study adhered to the following ethical principles: 
Ethical clearance was obtained from the Research Ethics Committee of the Faculty of Humanities of the University of Pretoria (Appendix A). Permission was also obtained from the Future Families NGO (Appendix B), as the CCWs from Future Families conducted the screening in their working communities.

Data is securely stored on an electronic database and will be kept for a minimum of 15 years at the University of Pretoria.

Informed consent

Voluntary informed consent was obtained from all participants. All participants were of legal age (18 years or older) and were able to provide consent. The consent form described the nature of the study and what participation entailed (Appendix $C$ and $D$ ). The consent form emphasised that participation was on a voluntary basis and that withdrawal was allowed at any time, without any negative consequences. Potential risks and benefits should be described clearly (Leedy \& Ormrod, 2015). This study contained no risks to the participants. The consent form (Appendix $C$ and $D$ ) was signed by all parties involved and participants received a copy upon request.

\section{Beneficence}

Participants were informed of the benefits they may receive from participation in the study. The caregivers would receive feedback regarding their child's development based on their concerns and therefore, if necessary, their children would be referred for the necessary therapeutic services. The CCWs would be more aware of the development of children under 40 months, with which they could educate and increase community awareness regarding development and developmental milestones, especially amongst caregivers. They would also become more comfortable with the use of mHealth, gain knowledge regarding screening tools and how to implement these tools to increase early detection and prevention of developmental delays.

\section{Non-maleficence}

Research participants were not in any way subject to physical or psychological injury, stress or embarrassment. The families of participants and the participants themselves were respected at all times. The CCWs collected the data at the participants' homes 
and in the caregiver's home language. According to the Constitution of the Republic of South Africa Act No. 108, 1996; the National Patient's Rights Charter, July 2002; the National Health Act No. 61, 2003 and the Promotion of Equality and Prevention of Unfair Discrimination Act (PEPUDA), Act No. 4, 2000, healthcare services should be made accessible and available to particular individuals and communities and that these services should be appropriate (SASLHA, 2011), including choice of language. Participants were allowed to withdraw from the study at any time, without any negative consequences.

\section{Confidentiality}

The participants' privacy and personal information were protected at all times and their test outcomes and feedback were kept strictly confidential (Leedy \& Ormrod, 2015). Each caregiver received a number to ensure anonymity. The information leaflet (Appendix C) stated that confidentiality will be ensured. The $\mathrm{CCW}$ s received adequate training to equip them in explaining the information described in the leaflet.

\section{$2.4 \quad$ Research Setting}

Data was collected in Mamelodi, Gauteng, South Africa. Mamelodi has approximately 334577 inhabitants and is currently one of the biggest poverty-stricken urban populations in the City of Tshwane, the administrative capital of South Africa (Statistics South Africa, 2011). According to Future Families (2016), 2600 children in Mamelodi are either orphaned or considered as vulnerable. Future Families, an NGO with a satellite office in Mamelodi, supports families with children who have either all been infected or affected by HIV/AIDS. These families are visited by their CCWs on a fortnightly basis. CCWs employed by Future Families conducted home visits to screen and rescreen all children who met the criteria.

\subsection{Participants}

Participants in the study were categorised into two groups, namely CCWs and the caregivers and their children. 
Community care workers (CCWs)

There are approximately 10 CCWs working for the Mamelodi division of Future Families. All CCWs were asked to participate in the study (Appendix D). The CCWs employed by Future Families have a minimum education level of Grade 12. Their ages ranged from 32 to 64 years (mean 43.9; SD 10.6). CCWs are already part of various programmes training them in healthcare service provision, such as hearing screening (Hussein et al., 2015). They were trained to use and administer the PEDS screening application. One hundred and thirty-eight screens and 85 rescreens were conducted. Each CCW administered between 11 and 18 (mean=13.8; SD=2.1) screens and between four and 13 (mean=8.5; $\mathrm{SD}=2.8$ ) rescreens.

Caregivers and their children

All families with children between the ages of one month and 38 months, supported by Future Families, were invited to participate in the study (Appendix C). This age group was selected to suit the age cohort of the PEDS tools application. Approximately 138 children were identified as meeting the inclusion criteria and were interviewed by the CCWs.

In order for families to participate in the study, the following inclusion criteria needed to be met:

- The consent form (Appendix C) should have been signed by the caregiver prior to the screening.

- All children screened, male and female, should be between the ages of one month and 38 months.

- The caregiver should be literate in order to complete the background information questionnaire (Appendix E).

\subsection{Materials and apparatus}

The PEDS tools, i.e. PEDS (Glascoe, 2013b) and the PEDS: DM (Brothers et al., 2008) are developmental screening tools based on parental report and were used to collect data. The PEDS tools consist of 16 multiple choice questions and take approximately 10-15 minutes to complete. The PEDS tools have previously been used within a setting much like Mamelodi (van der Linde et al., 2016). The questions were 
well understood (van der Linde et al., 2016) indicating its appropriateness in this type of setting.

The PEDS tools have validated referral algorithms. The outcome of the PEDS tools are interpreted using five evidence-based pathways, which either pass or refer a child based on the type and/or amount of parental concerns (Figure 1) (Glascoe, 2013a).

\begin{tabular}{|c|c|c|c|}
\hline Path A & Path B & Path C & Path D \\
\hline $\begin{array}{l}\text { - Two or more } \\
\text { predictive } \\
\text { concerns } \\
\text { - Immediate } \\
\text { referral for } \\
\text { diagnostic } \\
\text { assessment }\end{array}$ & $\begin{array}{l}\text { - One predictive } \\
\text { health concern } \\
\text { - Second screen } \\
\text { recommended }\end{array}$ & $\begin{array}{l}\text { - Non-predictive } \\
\text { concerns } \\
\text { - Provide } \\
\text { counselling }\end{array}$ & $\begin{array}{l}\text { - Parents have } \\
\text { difficulty } \\
\text { communicating } \\
\text { their concerns }\end{array}$ \\
\hline
\end{tabular}

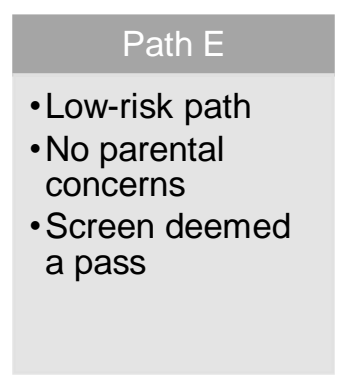

Figure 1. Evidence-based pathways of the PEDS (Glascoe, 2013a).

The combination of the PEDS and PEDS:DM (i.e. PEDS tools) is used to prevent false negatives, especially in high risk populations such as Mamelodi (Glascoe, 2013a). Using this referral criteria reduced false negatives by $12 \%$ in a previous study conducted within a high risk population (Glascoe, 2013a). For the purpose of this study, all children failed the screen and rescreen when they received a Path $A$ result from the PEDS. Children were referred when three or more concerns were identified by the PEDS:DM, regardless of the path identified by their PEDS result, as was suggested by the author of the tools (Glascoe, 2013a).

The PEDS tools (PEDS used in concurrence with PEDS:DM for both the screen and rescreen) were recently developed into a smartphone application using the same algorithm as the original paper-based tool (Maleka et al., 2016). For the purpose of this study, the application based tools were used. Almost perfect agreement (99\%) was found between the screening outcome, administered by a CHW, and the paperbased version, administered by a Speech-Language therapist (Maleka et al., 2016). The application was developed and piloted by the University of Pretoria. It was written as a native Android application in Java making use of the Android Software Development Kit (SDK). The PEDS application was installed on ten Vodacom Smart mini 7 smartphones (Android OS 6.0). Data is automatically saved on a secure server on the phone and presented in MS Excel. 
Background information questionnaires (Appendix E) were completed by each caregiver in order to obtain their biographic and demographic information for an accurate description of the population. The CCWs were required to complete a five point Likert Scale questionnaire, ranging from strongly agree to strongly disagree, over nine questions (Appendix $F$ ), regarding their perceptions of the mHealth screening programme. An existing questionnaire has been amended (van der Linde, Swanepoel, Glascoe, Louw, \& Vinck, 2015) to suit this study. The amendment was suitable and had no effect on validity.

\subsection{Procedures for data collection}

The procedure for data collection was as follows:

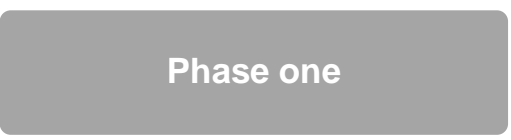

Trained CCWs on adminstering PEDS application (3-4 hours)

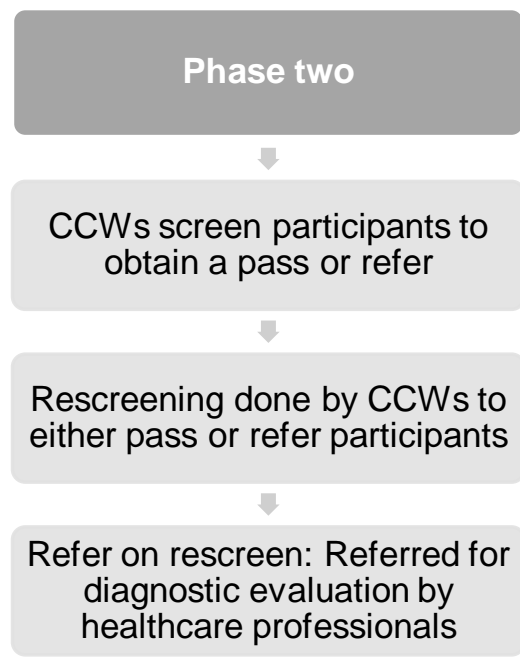

Phase two

Phase three

Questionnaire completed by CCWs

Figure 2. Phases of the implementation of the screening programme

\subsubsection{Phase one}

Ethical clearance from the Humanities Ethics Committee from the University of Pretoria was received (Appendix A). Permission was obtained from Future Families (Appendix B) and data collection commenced. This phase was conducted by the CCWs. The CCWs employed by Future Families signed the informed consent forms (Appendix D) after agreeing to partake in the study. They were then trained by the researcher on how to administer the PEDS tools and how to explain the informed consent letter to the participants. 


\subsubsection{Phase two}

Each CCW approached the caregivers of the children within the specified age range (0-38 months). The CCW explained the study and importance of developmental screening to the caregivers of the identified children. The caregiver received detailed information regarding the study, either by reading the information leaflet (in English) or verbally from the CCW, in a language of their choice. After voluntarily agreeing to participate in the study, the caregiver was required to sign the consent letter and information leaflet (Appendix $\mathrm{C}$ ) explaining the aim of the study and confidentiality agreement. After consent was obtained, each caregiver was required to complete a background information questionnaire (Appendix E). On completion of the background information questionnaire, developmental screening was completed in the caregiver's preferred language (Figure 2).

The children who failed the first screen were rescreened by the same CCW within 14 days (at the next home visit). Rescreening was done to ensure that children were not unnecessarily referred for a diagnostic evaluation. The children who failed the rescreen were then referred for a comprehensive diagnostic evaluation.

\subsubsection{Phase three}

Upon completion of the rescreening, the CCWs were requested to complete a questionnaire (Appendix F), containing a five-point Likert Scale over nine questions, regarding their perceptions of the mHealth screening programme and its sustainability. Space was provided for any additional comments or recommendations with regards to the screening process. The questionnaires were completed anonymously.

Figure 3 illustrates the process from the screen to the rescreen and further referral for diagnostic evaluation. 




Figure 3. Stages of the screen and rescreen process facilitated by CCWs.

\subsection{Data processing}

Data processing involves the preparation of data for analysis, by categorizing it in an orderly manner (Robson, 2011). This is done by coding the raw data in a quantifiable way (deVos, Strydom, Fouche, \& Delport, 2002). During phase two of the study, data were extracted from the PEDS cloud-based server to an MS Excel sheet for statistical analysis. The participants' background information questionnaires were recorded in a MS Excel sheet as quantitative data for statistical analysis. After phase three, data from the CCW questionnaires were processed as both quantitative and qualitative data in a MS Excel sheet, and analysed accordingly.

\subsection{Data analysis}

Descriptive and inferential statistics were employed to describe and analyse the quantitative data (Irwin, Pannbacker, \& Lass, 2008). The Statistic Package Social Sciences (SPSS) v 23 (Chicago, Illinois) was used for statistical calculations and analysis. The results were divided into two age groups, 0-18 months and 19-38 months, in order to cross-tabulate the PEDS tools outcomes with the different ages. Pearson Chi-Square tests were used to determine the significance between the 
screens and rescreen results. A correlation coefficient of $p \leq 0.05$ (Robson, 2011) was used to determine statistical significance. Thematic analysis (deVos et al., 2002) was employed to analyse the qualitative data describing the perceptions of the CCWs. This method is used to meaningfully organise the responses by identifying and coding the comments (deVos et al., 2002). They were then divided into three themes.

\subsection{Reliability and validity}

The PEDS was standardized in 2012 on a sample of 47531 families in Canada and the United States. The PEDS was validated and deemed reliable on at least 4500 children across various settings (Glascoe, 2013a). In validity studies from 2012, the PEDS tool presented with content validity, construct validity, concurrent validity and predictive validity (Glascoe, 2013a). In more than 20 studies, the sensitivity of the PEDS was greater than $80 \%$. PEDS in nations other than the United States showed a high sensitivity and specificity to developmental problem (Glascoe, 2013a). The PEDS tools application yielded a high inter-rater agreement $(\kappa=0.960$; Cohen's Kappa) when comparing outcomes obtained between CHWs and SLTs (Maleka et al., 2016), deeming the results reliable when the application is operated by CCWs and applied to a vulnerable population. 


\section{EARLY DETECTION OF DEVELOPMENTAL DELAYS IN VULNERABLE CHILDREN BY COMMUNITY HEALTH WORKERS USING AN MHEALTH TOOL}

Authors: Maria van der Merwe, Renata Mosca, De Wet Swanepoel (PhD), Frances Glascoe (PhD), Jeannie van der Linde (PhD)

Journal: $\quad$ Family and Community Health ${ }^{1}$

Submitted: 29 September 2017

\subsection{Abstract}

Introduction: Developmental delays are increasing worldwide, as a result of exposure to environmental risk factors. Early detection services are often inaccessible in lowand middle income countries (LMIC) due to limited human resources and a lack of knowledge regarding development. This study investigated an mHealth screening programme with community care workers (CCWs) facilitating early detection of developmental delays in children from underserved communities.

Method: CCWs, employed by a community-based non-governmental organization (NGO), were trained to administer the Parents' Evaluation of Developmental Status (PEDS) smartphone application as part of home-based services offered to families affected by HIV/AIDS. After the training, 138 children (mean=19.2 months, $S D=11.1$ ) were screened in the community. Children who failed the screen were rescreened and referred for diagnostic assessment if the rescreen also produced a fail. CCWs completed a questionnaire regarding their perceptions and experiences of communitybased mHealth-assisted screening.

Results and discussion: The overall referral rate was 69\%. Older children (19-38 months old) had a significantly higher $(\mathrm{p}<0.05$; Chi-Square) referral rate $(84 \% ; n=39)$ compared to those aged $0-18$ months $(52 \% ; n=24)$. The high referral rate may be attributed to the at-risk population sampled. Average screening time was 12.5 minutes and on average ten children were screened per day. CCWs perceived mHealth screening as valuable in terms of utility, outcomes and contribution to developmental knowledge for community members and CCWs. Community-based services are a

${ }^{1}$ This article was edited in accordance with the editorial specifications required by the journal and may differ from the editorial style of the rest of this document. 
promising platform to implement mHealth-assisted early developmental screening programmes.

Conclusion: CCWs and mHealth-assisted developmental screening can facilitate better access to early detection and developmental surveillance for vulnerable children and their families. CCWs indicated that they were motivated to promote increased developmental surveillance.

Key words: Development, screening, community health workers, mHealth

\subsection{Introduction}

Worldwide developmental delays are increasing. ${ }^{[1]}$ Poverty and exposure to environmental risk factors contribute to the increase, especially in vulnerable populations. ${ }^{[2]}$ Developmental screening from birth through childhood is essential for the early identification of developmental delays in vulnerable children. However, these services are often inaccessible in primary healthcare $(\mathrm{PHC})$ and community-based contexts, due to limited facilities and resources. ${ }^{[3,4]}$

The use of developmental screening tools has received attention in recent literature in response to the global rise in developmental disorders. ${ }^{[2]}$ Prioritisation of developmental screening, especially in low- and middle income countries (LMICs) such as South Africa, ${ }^{[5]}$ is challenged by the global burden of disease, including HIV/AIDS, tuberculosis, and high child mortality rates. ${ }^{[6]}$ Additionally, culturally and linguistically applicable standardised developmental screening tools are lacking. ${ }^{[7]}$ In a country such as South Africa, the only national developmental screening tool that has been implemented, the Road to Health Booklet (RTHB), has not yet been validated. ${ }^{[8]}$ A recent study reported that the RTHB failed to identify the majority of infants at risk for a developmental delay due to its low sensitivity as developmental domains are not evaluated consistently across all age ranges. ${ }^{[8]}$ Furthermore, the referral framework of the RTHB screen is insufficient, since no indication is given to whom children should be referred to and for which services. ${ }^{[9]}$

PHC personnel tasked with conducting developmental screening as part of well-baby clinics, regularly lack the knowledge to correctly identify and refer children with developmental delays. ${ }^{[7]}$ This can be ascribed to, amongst other factors, limited knowledge regarding the scope of practice of allied healthcare professionals and as a result may hamper appropriate referrals. ${ }^{[7]}$ Furthermore, $\mathrm{PHC}$ personnel are 
overburdened with high caseloads resulting in less hands-on care available to children. ${ }^{[2]}$

Community health workers (CHWs) potentially serve as the missing link between healthcare systems and underserved, culturally and linguistically diverse communities. CHWs provide alternative access to vital healthcare, particularly for vulnerable populations. ${ }^{[10]}$ Internationally, CHWs are defined as community workers who "promote health within a community by assisting individuals to adopt healthy behaviours... who may deliver health related preventative services such as hearing screenings". ${ }^{[11]}$ In many South African studies, they are also referred to as community care workers (CCWs). ${ }^{[12,13,14,15]} \mathrm{CCW}$ s play an unprecedented role in the social welfare of community members, in addition to focusing on health needs. ${ }^{[16]}$ No clear distinctions between these terms (CHWs vs CCWs) exist across current literature, mainly due to tasks that are formally or informally added to their job description. ${ }^{[17]}$

Since 2010, the community oriented primary care (COPC) initiative, an example of CHWs' inclusion in healthcare service delivery, has been implemented in Gauteng, South Africa to help alleviate the burden on PHC professionals in underserved communities. ${ }^{[18]} \mathrm{CHWs}$ can provide direct health services that are culturally and linguistically appropriate, such as developmental screening, and increase caregiver awareness of early childhood development. ${ }^{[19]}$ Despite these benefits, CHWs face many challenges, including funding, printing and processing paper-based instruments, and timely manual analysis of collated information. ${ }^{[20,21]}$

Recently, CHWs have been using mHealth tools to deliver healthcare services. ${ }^{[22]}$ Costs associated with paper-based instruments can be reduced and data can be digitised through mHealth technology. The universal use of mHealth in healthcare is rapidly expanding. ${ }^{[23]}$ Despite initial concerns regarding the feasibility of mHealth in LMICs, a few studies have proven its effectiveness. ${ }^{[24]}$ In India and Zambia, mHealth is currently used to screen and diagnose cancer patients. ${ }^{[24]} \mathrm{mHealth}$ is accessible in most low-income settings due to the growing availability of mobile phone technology. ${ }^{[25]}$ A study conducted in 2015 reviewed cell phone ownership across 40 countries and reported that almost all (90\%) South African adults have a cellphone. ${ }^{[26]}$ mHealth may be a viable approach to expand community-based developmental 
screening. A developmental screening tool using mHealth technology administered by CCWs is a low-cost option for decentralised access to early detection.

The Parents' Evaluation of Developmental Status (PEDS ${ }^{[27]}$ and the Parents' Evaluation of Developmental Status: Developmental Milestones (PEDS: DM) ${ }^{[28]}$ are parent-administered screening tools that have recently been adapted for use as mHealth tools. ${ }^{[9]}$ The PEDS used in combination with the PEDS: DM is proven to be an accurate approach to developmental screening. ${ }^{[29]}$ Currently there is limited evidence regarding the role of CCWs in the developmental screening of children, especially using mHealth technology such as the PEDS tools. The objective of this study was to describe the clinical utility, in terms of referral rate, test duration and early detection of developmental delays, of an mHealth-assisted developmental screening programme by CCWs, and their perceptions regarding the programme.

\subsection{Method}

Study objective: To describe the clinical utility and perceived value of a CCWadministered mHealth screening programme for early detection of developmental delays in vulnerable populations. Clinical utility will be examined in terms of referral rate, test duration and early detection.

\section{Setting and participants}

Data was collected in Mamelodi, Gauteng, South Africa. Mamelodi is one of the largest poverty-stricken urban populations in the City of Tshwane, the administrative capital of South Africa. ${ }^{[30]}$ Two participant groups were included in the study; CCWs and the families assigned to the CCWs. Future Families, a community based nongovernmental organization (NGO), supports families with children who are either infected or affected by HIV/AIDS. The CCWs are employed to provide healthcare and welfare services within their communities. Their primary role is to create awareness, promote prevention and address issues pertaining to HIV/AIDS and anti-retroviral (ARV) treatment, nutrition, immunisation and parenting skills. Ten accredited CCWs from the Mamelodi division of Future Families were invited to participate in the study. Their ages ranged from 32 to 64 years (mean 43.9; SD 10.6). One hundred and thirty eight screens and 85 rescreens were conducted. Each CCW administered between 
11 and 18 (mean=13.8; SD=2.1) screens and between four and 13 (mean=8.5; $\mathrm{SD}=2.8$ ) rescreens.

All the families connected to Future Families with children between the ages of one and 38 months were invited to participate in the study. There were 138 families selected to participate and who were interviewed by the CCWs.

\section{Materials and apparatus}

The PEDS tools, i.e. PEDS ${ }^{[27]}$ and the PEDS: DM ${ }^{[28]}$, consist of 16 multiple choice questions and take approximately 10-15 minutes to complete. These tools were recently developed into a smartphone application by the University of Pretoria using the same algorithm as the original paper-based tool. ${ }^{[9]}$ Almost perfect agreement (99\%) was found between the screening outcome, administered by a CCW, and the paper-based version, administered by a speech-language therapist. ${ }^{[9]}$ It was written as a native Android application in Java making use of the Android Software Development Kit (SDK). The PEDS application was installed on ten Vodacom Smart mini 7 smartphones (Android OS 6.0). Data automatically save to the phone and can be downloaded as an MS Excel file.

The PEDS tools have validated referral algorithms. The outcome of the PEDS tools are interpreted using five evidence-based pathways, which either pass or refer a child based on the type and/or amount of parental concerns (Figure 1). ${ }^{29]}$

$\quad$ Path A
- Two or more
predictive
concerns
- Immediate
referral for
diagnostic
assessment
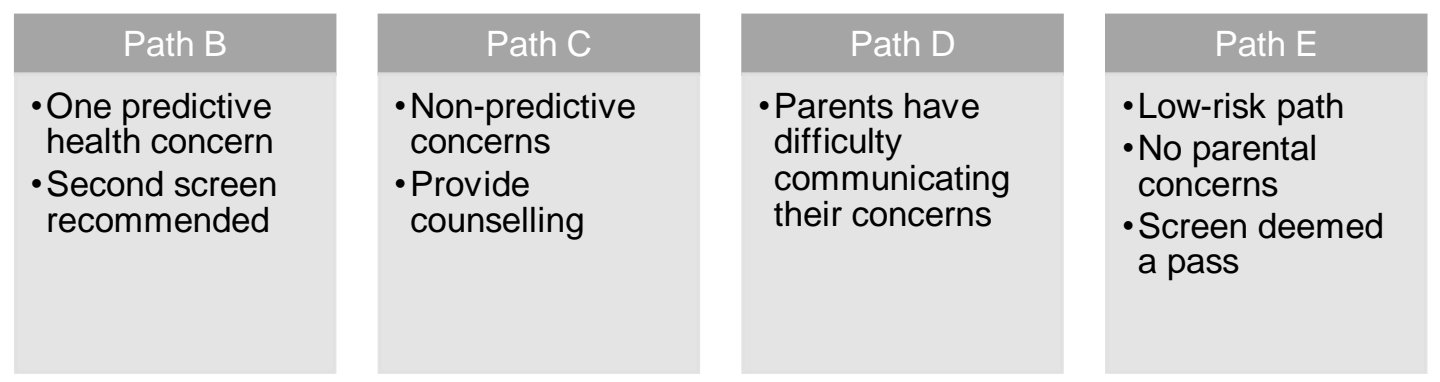

Figure 1. Evidence-based pathways of the PEDS ${ }^{[29]}$

The combination of the PEDS and PEDS:DM (i.e. PEDS tools) is used, for both the screen and rescreen, to prevent false negatives, especially in high risk populations such as Mamelodi. ${ }^{[29]}$ Using this referral criteria reduced false negatives by $12 \%$ in a previous study conducted within a high risk population. ${ }^{[29]}$ For the purpose of this study, all children failed the screen when they received a Path A result from the PEDS. Children were referred when three or more concerns were identified by the PEDS:DM, 
regardless of the path identified by their PEDS result, as was suggested by the author of the tools. ${ }^{[29]}$

Additionally, caregivers completed background information questionnaires to gather demographic and biographic information. A five point rating scale, ranging from strongly agree to strongly disagree, of nine questions was used to determine CCWs' perceptions of the mHealth screening programme. ${ }^{[8]} A$ section was included where additional comments or recommendations could be made.

\section{Procedures}

IRB approval was obtained. Once informed consent was obtained, the CCWs were trained to administer the PEDS tools. CCWs then approached the caregivers of the children within the specified age range (0-38 months). After informed consent was obtained from the caregivers, background information questionnaires and developmental screening were completed in the caregiver's preferred language (Figure 2).

Children who failed the screen were rescreened by the same CCW within 14 days. The children who failed the rescreen were then referred for a comprehensive diagnostic evaluation. Upon completion of rescreening, the CCWs completed the five point rating scale questionnaire regarding their perceptions of the mHealth screening programme. All CCWs completed the questionnaire on the day the phones were collected.

\section{Data analysis}

Descriptive and inferential statistics were employed to describe and analyse quantitative data. ${ }^{[31]}$ The Statistic Package Social Sciences (SPSS) v 23 (Chicago, Illinois) was used for statistical calculations and analysis. Data were extracted from the PEDS cloud-based server to an MS Excel sheet. Cross-tabulations were used to compare the combined outcomes of the PEDS tools. Results were divided into two age categories (0-18 months and 19-38 months). Pearson Chi-Square tests were used to evaluate the differences between outcomes of screens and rescreens. Thematic analysis ${ }^{[32]}$ was employed to analyse qualitative data describing the perceptions of the CCWs, obtained from the questionnaire. This method is used to meaningfully organise 
the responses by identifying and coding the comments. Responses were then divided into three themes.

\subsection{Results}

The average age of the children (Table 1) was 19.2 months (SD 11.1). Of the families that indicated their monthly income $(n=114), 78 \%(n=89)$ received a nett income of less than $\$ 155$ per month. The number of occupants per household ranged from two $(4 \%)$ to more than 10 (17\%), whereas most of the households $(76 \% ; n=105)$ had more than three children per household.

Table 1: Demographic information of participants

\begin{tabular}{|c|c|}
\hline & Percentage \\
\hline \multicolumn{2}{|l|}{ Children age $(n=138)$} \\
\hline $0-18$ months & $46 \%(n=64)$ \\
\hline 19-38 months & $54 \%(n=74)$ \\
\hline \multicolumn{2}{|l|}{ Children Gender ( $n=138)$} \\
\hline Male & $51 \%(n=70)$ \\
\hline Female & $49 \%(n=68)$ \\
\hline \multicolumn{2}{|l|}{ Primary caregivers $(n=138)$} \\
\hline Mother & $79 \%(n=109)$ \\
\hline Father & $1 \%(n=2)$ \\
\hline Family members & $20 \%(n=27)$ \\
\hline \multicolumn{2}{|l|}{ Caregiver age $(n=135)^{\star}$} \\
\hline Younger than 30 years & $47 \%(n=63)$ \\
\hline $31-40$ years & $33 \%(n=44)$ \\
\hline 41 and older years & $20 \%(n=28)$ \\
\hline \multicolumn{2}{|l|}{ Home languages $(n=138)$} \\
\hline Sepedi & $38 \%(n=53)$ \\
\hline isiZulu & $19 \%(n=26)$ \\
\hline Tsonga & $15 \%(n=20)$ \\
\hline SiSwati & $9 \%(n=12)$ \\
\hline isiNdebele & $7 \%(n=9)$ \\
\hline Other & $12 \%(n=18)$ \\
\hline
\end{tabular}

Caregiver employment $(\mathrm{n}=137)^{\star}$ 


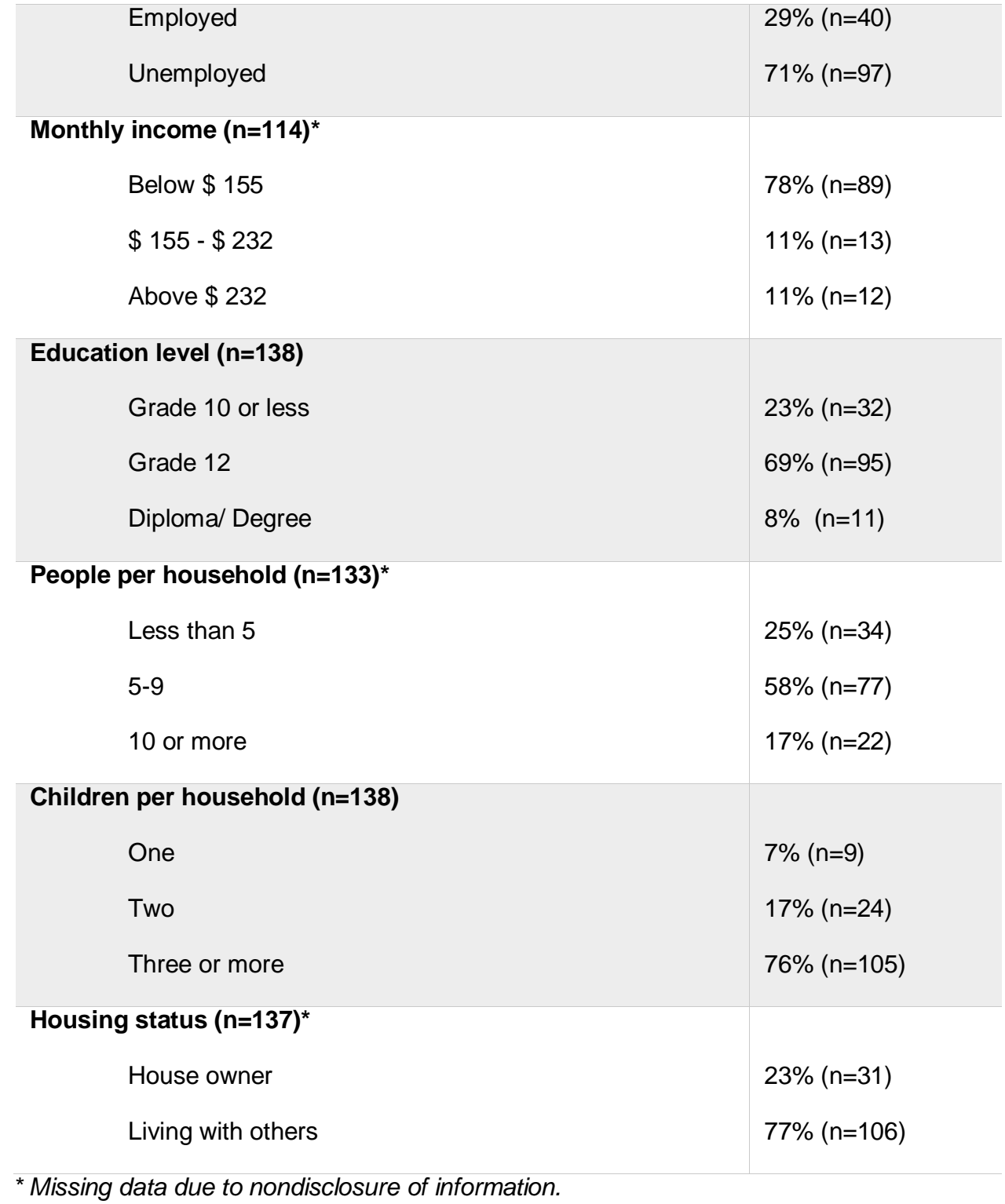

A total of 138 children were screened by the CCWs using the mHealth PEDS tools. Figure 2 illustrates the process from the screen to the rescreen and further referral for diagnostic assessment. 


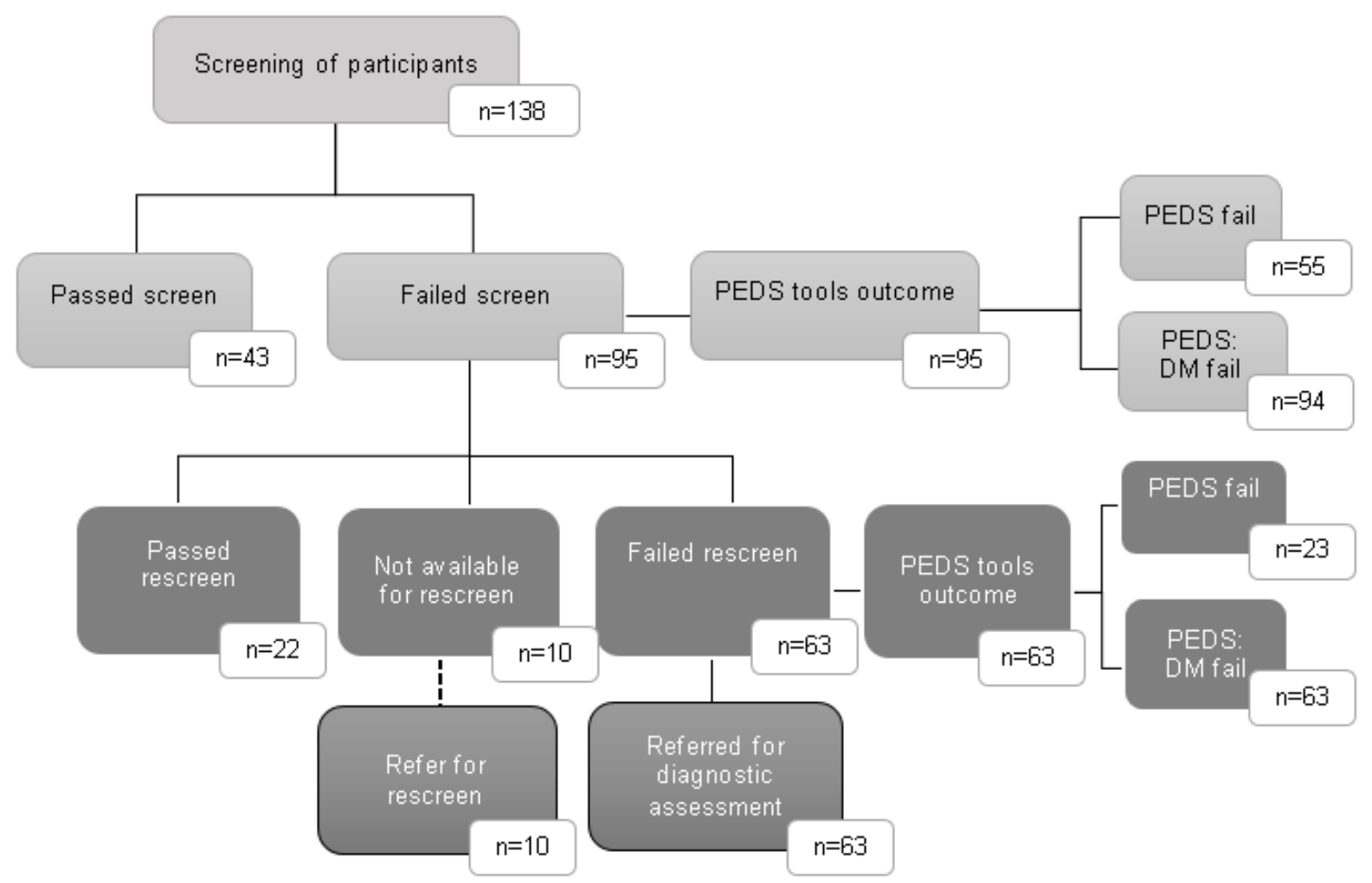

Figure 2. Stages of the screen and rescreen process facilitated by CCWs.

The overall referral rate (Table 2$)$ of the PEDS tools was $69 \%(n=95)$. The overall referral rate of the PEDS tools was significantly higher $(p<0.05$; Chi-Square) for the older age group ( $84 \% ; n=62)$ when compared to the younger age group $(52 \% ; n=33)$. The referral rate of the PEDS:DM $(68 \% ; n=94)$ compared to the PEDS $(40 \% ; n=55)$ was higher (Table 2), although not significantly ( $p>0.05$; Chi-Square).

\begin{tabular}{|c|c|c|c|}
\hline Age group & $\begin{array}{l}\text { PEDS tools } \\
\text { referral rate }\end{array}$ & $\begin{array}{l}\text { PEDS:DM } \\
\text { referral rate }\end{array}$ & $\begin{array}{l}\text { PEDS } \\
\text { referral rate }\end{array}$ \\
\hline $0-18$ months & $52 \%$ & $52 \%$ & $28 \%$ \\
\hline$(n=64)$ & $(n=33)$ & $(n=33)$ & $(n=18)$ \\
\hline $19-38$ months & $84 \%$ & $82 \%$ & $50 \%$ \\
\hline$(n=74)$ & $(n=62)$ & $(n=61)$ & $(n=37)$ \\
\hline TOTAL REFERRED & $69 \%$ & $68 \%$ & $40 \%$ \\
\hline$(n=138)$ & $(n=95)$ & $(n=94)$ & $(n=55)$ \\
\hline
\end{tabular}

Of the referred participants $(n=95), 89 \%(n=85)$ were available at the time of rescreen. Results of children unavailable for rescreening $(11 \% ; n=10)$ were disregarded when comparing the screen and rescreen results (Table 3 ). The PEDS rescreen referral rate 
(27\%; $n=23)$ was significantly lower $(p<0.05)$ compared to the PEDS screen referral rate $(35 \% ; n=45)$.

Table 3: Distribution of referral rates across screen (S) and rescreen (RS) within age categories

\begin{tabular}{|c|c|c|c|c|c|c|}
\hline Age group & $\begin{array}{c}\text { PEDS } \\
\text { tools S } \\
\left(n=128^{\star}\right)\end{array}$ & $\begin{array}{c}\text { PEDS } \\
\text { tools RS } \\
(\mathrm{n}=85)\end{array}$ & $\begin{array}{c}\text { PEDS:DM } \\
S(n=128)\end{array}$ & $\begin{array}{l}\text { PEDS:DM } \\
\text { RS }(n=85)\end{array}$ & $\begin{array}{l}\text { PEDS S } \\
(n=128)\end{array}$ & $\begin{array}{c}\text { PEDS } \\
\text { RS } \\
(n=85)\end{array}$ \\
\hline $\begin{array}{c}0-18 \text { months } \\
\left(S^{\star} n=60 ;\right. \\
\left.R^{\star * *} n=30\right)\end{array}$ & $\begin{array}{c}48 \% \\
(n=29)\end{array}$ & $\begin{array}{c}80 \% \\
(n=24)\end{array}$ & $\begin{array}{c}48 \% \\
(n=29)\end{array}$ & $\begin{array}{c}80 \% \\
(n=24)\end{array}$ & $\begin{array}{c}23 \% \\
(n=14)\end{array}$ & $\begin{array}{l}23 \% \\
(n=7)\end{array}$ \\
\hline $\begin{array}{c}19-38 \text { months } \\
S^{\star} n=68 ; \\
\left.R^{* \star \star} n=55\right)\end{array}$ & $\begin{array}{l}82 \% \\
(n=56)\end{array}$ & $\begin{array}{c}71 \% \\
(n=39)\end{array}$ & $\begin{array}{c}81 \% \\
(n=55)\end{array}$ & $\begin{array}{c}71 \% \\
(n=39)\end{array}$ & $\begin{array}{c}46 \% \\
(n=31)\end{array}$ & $\begin{array}{l}29 \% \\
(n=16)\end{array}$ \\
\hline $\begin{array}{c}\text { TOTAL } \\
\text { REFERRED }\end{array}$ & $\begin{array}{c}66 \% \\
(n=85)\end{array}$ & $\begin{array}{c}74 \% \\
(n=63)\end{array}$ & $\begin{array}{c}66 \% \\
(n=84)\end{array}$ & $\begin{array}{c}74 \% \\
(n=63)\end{array}$ & $\begin{array}{l}35 \% \\
(n=45)\end{array}$ & $\begin{array}{l}27 \% \\
(n=23)\end{array}$ \\
\hline
\end{tabular}

${ }^{*}$ Results of ten participants disregarded

Mean test duration recorded for the screen was 12.5 minutes (SD 3.1 minutes) and 13.9 minutes (SD 4.5 minutes) for rescreen. The CCWs that were older than 40 years $(50 \% ; n=5)$ took significantly longer ( $p<0.05$; Chi-Square) to rescreen with an average of 15.4 minutes (SD 4.4 minutes) compared to younger CCWs $(50 \% ; n=5)$, with an average rescreen time of 12.5 minutes (SD 3.7 minutes). Over a period of 14 days, CCWs screened an average of ten children per day (SD 7.02). CCWs completed the mHealth screening process within one month.

All CCWs (100\%; $n=10)$ indicated on the questionnaire that developmental screening can have a positive impact in the community (Table 4) as it was easy to use in the home environment (90\%; $n=9)$ and caregivers understood the questions asked $(100 \%$, $\mathrm{n}=10$ ). No responses were reported in the categories 'disagree' and 'strongly disagree' on the questionnaire completed by the CCWs regarding their perceived value of an mHealth supported screening programme (Table 4). 
Table 4: CCWs' perceptions regarding value of an mHealth screening programme $(n=10)$

\begin{tabular}{|llll|}
\hline \multicolumn{1}{|c}{ Questions } & $\begin{array}{c}\text { 1- } \begin{array}{c}\text { Strongly } \\
\text { agree } \\
\text { 1. App instructions clear }\end{array} \\
90 \%(n=9)\end{array}$ & 2- Agree & 3- Neutral \\
\hline 2. Adequate training & $60 \%(n=6)$ & $40 \%(n=4)$ & $10 \%(n=1)$ \\
\hline 3. Easy to administer & $70 \%(n=7)$ & $10 \%(n=1)$ & $20 \%(n=2)$ \\
\hline 4. Easy to administer in homes & $60 \%(n=6)$ & $30 \%(n=3)$ & $10 \%(n=1)$ \\
\hline 5. Quick to administer & $80 \%(n=8)$ & $20 \%(n=2)$ & \\
\hline 6. Caregivers understood questions & $50 \%(n=5)$ & $50 \%(n=5)$ & $10 \%(n=1)$ \\
\hline 7. Accurate results & $80 \%(n=8)$ & $20 \%(n=2)$ & \\
\hline 8. Caregivers agree with final results? & $70 \%(n=7)$ & $20 \%(n=2)$ & \\
\hline 9. Positive impact on community? & $100 \%(n=10)$ & & \\
\hline
\end{tabular}

Thematic analysis of the CCWs' comments on the open-ended questions of the questionnaire identified three main themes (Table 5). The reported benefits of the mHealth tools included early referral, the positive impact on the community and the importance of developmental screening and surveillance. The CCWs reported increased knowledge regarding typical development and the importance of developmental surveillance. The perceived value of the screening programme was highlighted including aspects such as time-efficiency, convenience, practicality and overall enjoyable experience.

Table 5: Thematic analysis of CCW's comments regarding screening programme

\begin{tabular}{|c|c|}
\hline Themes & Comments \\
\hline $\begin{array}{ll}\text { Benefit for children } \\
\text { community }(n=11)\end{array}$ & $\begin{array}{l}\text { - "positive impact to our community" } \\
\text { - "they want to do even older children from 4-6 years before they start school" } \\
\text { - "if the child need help he will be refer early" } \\
\text { - "so that we can know how the child is growing" }\end{array}$ \\
\hline $\begin{array}{l}\text { Knowledge } \\
\text { development } \\
(\mathrm{n}=8)\end{array}$ & $\begin{array}{l}\text { - "I learned so much about development" } \\
\text { - "I did not know that each and every stage is very important to the child and } \\
\text { mother" } \\
\text { - "I have learnt a lot myself. Thank you UP" }\end{array}$ \\
\hline $\begin{array}{l}\text { Perceived value of } \\
\text { mHealth-assisted } \\
\text { screening programme } \\
(n=10)\end{array}$ & $\begin{array}{l}\text { - "I think the screening was easy" } \\
\text { - "I have enjoyed a lot to assist" } \\
\text { - "I did enjoy it was fast" }\end{array}$ \\
\hline
\end{tabular}




\subsection{Discussion}

The clinical utility of this two-step screening process indicated a screen and rescreen fail rate of $69 \%$. The elevated overall referral rate of the PEDS tools $(69 \%)$ is likely attributable to this underserved populations' exposure to a range of environmental risk factors. ${ }^{[9 ; 33]}$ Environmental risk factors for developmental delay that were identified include low household income, caregiver unemployment and households with more than three children. ${ }^{[34,35,36,37,38]}$ Similar referral rates have been reported in other studies conducted in underserved communities. ${ }^{[9,33]}$ Yet, the global referral rate reported in a recent systematic review, was lower (32\%) ${ }^{[39]}$ than the rate in the current study. It should be taken into account that most of these studies were conducted in high-income countries. Risk exposure and its cumulative effect in vulnerable populations advocates the need for developmental screening to improve early detection of developmental delays. ${ }^{[35]}$ This may narrow the gap in children being unidentified at a younger age. ${ }^{[40]}$

Although not significant ( $p>0.05$; Chi-Square), the PEDS:DM overall referral rate $(68 \%)$ was higher than the PEDS overall referral rate $(40 \%)$. Parental lack of knowledge regarding different developmental domains may result in parents being unconcerned about possible developmental risks. ${ }^{[29]}$ Several studies found similar results, ${ }^{[29,39]}$ indicating the necessity of including a milestone-focused measure as part of a screening protocol, so as to discern delays that caregivers may not have identified. ${ }^{[29]}$ This supports the approach of using both the PEDS and PEDS:DM in combination when screening children from a high-risk population.

Test times, for both the screen and rescreen (mean 12.5 minutes), agree with the reported administration time of the paper-based PEDS tool. ${ }^{[34]}$ No previous studies have reported on the screening duration when using the PEDS application. Older CCWs took significantly longer $(p<0.05)$ to conduct the screening than their younger counterparts. This is likely partly a function of younger CCWs being more accustomed to smartphone technology. Screenings using mHealth may thus be implemented quicker by younger CCWs. Older CCWs may need more training to become more accustomed to smartphone technology. Another study conducted in primary healthcare settings reported screening times using paper-based instruments completed by CCWs that took an average of five minutes longer than in the current 
study. ${ }^{[41,42]}$ This suggests that the mHealth tool was time-efficient and effectively implemented by the trained CCWs in the current study.

CCWs completed the mHealth screening process within a period of one month (average of ten children per day). Most children (89\%) identified with concerns were rescreened within 14 days. Developmental screening administered by CCWs in the home setting has shown to have a positive impact on follow-up adherence. No transportation costs could impede their attendance at a PHC facility and only the caregiver were relied upon being present for the screening. Studies reported poor follow-up adherence in PHC settings of high risk families primarily due to logistical reasons and employment responsibilities. ${ }^{[43,44]}$ For this reason, mHealth screening in the home-setting may be an adequate model for service delivery in terms of early detection and close developmental surveillance.

CCWs $(100 \%)$ reported that the training to screen children was adequate and the application was easy to comprehend (90\%). Almost all CCWs $(90 \%)$ reported that caregivers agreed with the screening results. Over a third of the CCWs highlighted the need to educate the community regarding the importance of developmental screening (38\%) and this may be considered for future research.

CCWs indicated that they were motivated to promote increased developmental surveillance. A study reporting on the challenges perceived by healthcare professionals offering $\mathrm{PHC}$ services indicated limited time for training and service delivery, ${ }^{[45]}$ limited funds, lack of allocated space for services and shortages of nurses and PHC staff to conduct these services, leading to a lack in continuity of care. ${ }^{[46]} \mathrm{PHC}$ personnel felt demotivated due to these unrealistic workloads which compromise the quality of care they provide. ${ }^{[46]} \mathrm{CCW}$ using mHealth supported screening and developmental surveillance may reduce the burden on PHC personnel. It also appears to contribute to the knowledge of community members, which includes CCWs, ${ }^{[47,48]}$ by increasing awareness whilst developmental screening takes place.

Developmental screening for children older than 38 months was a future need identified by CCWs and caregivers in order to ensure early referral and improve future academic success. Future research should also be conducted to compare rescreen outcomes to comprehensive and diagnostic assessment results. 


\subsection{Conclusion}

Several studies have reported the effectiveness of $\mathrm{CHWs}$ in conducting mHealth screening programmes. ${ }^{[9,22,25,42,49,50]}$ This study demonstrated the potential of CCWs to use mHealth tools to reduce the demand on overburdened health professionals in typical healthcare settings. Findings indicate that many children can be screened in a short period of time, resulting in early and accurate referral to the appropriate healthcare professionals. mHealth screening programmes can improve universal access to developmental screening and surveillance by bringing services into the homes of vulnerable populations through minimally trained persons.

\section{Compliance with Ethical Standards:}

Conflict of Interest: The authors declare that they have no conflict of interest.

\subsection{References}

1. Schonhaut, L., Armijo, I., Schonstedt, M., Alvarez, J., Cordero, M. (2013). Validity of the Ages and Stages Questionnaires in term and preterm infants. Pediatrics, 131(5), e1468-e1474. http://dx.doi.org/10.1542/peds.2012-3313.

2. Donald, K., Hall, D., Dawes, A. (2012). Detecting and addressing developmentalbehavioral problems in primary care (pp. 405-408) Baltimore, Maryland: Brookes.

3. Samuels, A., Slemming, W., Balton, S. (2012). Early childhood intervention in South African in relation to the developmental systems model. Infants \& Young Children, 25(4), 334-345. http://dx.doi.org/10.1097/IYC.0b013e3182673e12.

4. Preston, R., Waugh, H., Larkins, S., Taylor, J. (2010). Community participation in rural primary care. Australian Journal of Primary Health, 16, 4-16. http://dx.doi.org/ 10.1071/PY09053.

5. Smith, T.R. (2016). Developmental surveillance and screening and the electronic health record. Pediatric Clinic of North America, 63(5), 933-934. http://dx.doi.org/10.1016/j.pcl.2016.06.014. 
6. Mayosi, B., Benatar, S. (2014). Health and healthcare in South Africa- 20 years after Mandela. The New England Journal of Medicine, 371 (14), 1344-1353. http://dx.doi.org/10.1016/ S0140-6736(12)61814-5.

7. Van der Linde, J., Kritzinger, A., Redelinghuys, A. (2009). The identification process in early communication intervention followed by primary health care personnel in Ditsobotla sub-district. The South African Journal of Communication Disorders, 56, 48-59.

8. Van der Linde, J., Swanepoel, D., Glascoe, F.P., Louw, E.M., Vinck, B. (2015). Developmental screening in South Africa: Comparing the national developmental checklist to a standardized tool. African Health Sciences, 15(1), 188-196. http://dx.doi.org/ 10.4314/ahs.v15i1.25.

9. Maleka, B.K., van der Linde, J., Glascoe, F.P., Swanepoel, D. (2016). Developmental screening- evaluation of an mHealth version of the Parents' Evaluation of Developmental Status tools. Telemedicine journal and e-Health: the official journal of the American Telemedicine Association, 22(12), 1013-1018. http://dx.doi.org/ 10.1089/tmj.2016.0007.

10. Johnson, S.L., Gunn, V.L. (2015). Community health workers as a component of the healthcare team. Pediatric Clinic of North America, 62(5), 1313-1328. http://dx.doi.org/10.1016/j.pcl.2015.06.004.

11. United States Bureau of Labor Statistics. (2017). Standard Occupational Classification. Retrieved from https://www.bls.gov/soc/\#revision (accessed 10 September 2017).

12. Friedman, I., Ramalepe, M., Matjuis, F., et al. (2007). Moving towards best practice: Documenting and learning from existing community health/care worker programmes. Durban: Health Systems Trust. 
13. Moshabela, M., Sips, I., Barten, F. (2015). Needs assessment for home-based care and the strengthening of social support networks: the role of community care workers in rural South Africa. Global Health Action, 8(1), 29265. http://dx.doi.org/10.3402/gha.v8.29265

14. Sips, I., Mazanderani, A.H., Schneider, H., Greeff, M., Barten, F., Moshabela, M. (2014). Community care workers, poor referral networks and consumption of personal resources in rural South Africa. PLoS ONE, 9(4), e95324. http://dx.doi.org/10.1371/journal.pone.0095324.

15. Okeyo, I., Dowse, R. (2016). Community care worker perceptions of their roles in tuberculosis care and their information needs. Health SA Gesondheid, 21, 245252. http://dx.doi.org/10.1016/j.hsag.2016.05.004

16. Pratt, K., Mbaligontsi, M. (2014). Transactional analysis transforms community care workers in South Africa. Transactional Analysis Journal, 44(1), 53-67. http://dx.doi.org/10.1177/0362153714531723.

17. Olaniran, A., Smith, H., Unkels, R., Bar-Zeev, S., van den Broek, N. (2017). Who is a community health worker? - A systematic review of definitions. Global Health Action, 10(1), 1272223. http://dx.doi.org/10.1080/16549716.2017.1272223.

18. Bam, N., Marcus, T., Hugo, J., Kinkel, H.F. (2013). Conceptualizing Community Oriented Primary Care (COPC) - The Tshwane, South Africa, health post model. African Journal of Primary Health Care \& Family Medicine, 5(1), 1-3. http://dx.doi.org/10.4102/phcfm.v5i1.423.

19. Brownstein, J.N., Hirsch, G.R., Rosenthal, E.L., Rush, C.H. (2011). Community health workers "101" for primary care providers and other stakeholders in health care systems. The Journal of ambulatory care management, 34(3), 210-220. http://dx.doi.org/10.1097/JAC.0b013e31821c645d. 
20. Liu, A., Sullivan, S., Khan, M., Sachs, S., Singh, P. (2011). Community health workers in global health: scale and scalability. Mount Sinai Journal of Medicine, 78, 419-435. http://dx.doi.org/10.1002/MSJ.

21. Neupane, S., Odendaal, W., Friedman, I., Jassat, W., Schneider, H., Doherty, T. (2014). Comparing a paper based monitoring and evaluation system to a mHealth system to support the national community health worker programme, South Africa: an evaluation. BMC Medical Informatics and Decision Making, 14(69), 1-9.

22. Agarwal, S., Perry, H.B., Long, L., Labrique, A.B. (2015). Evidence on feasibility and effective use of mHealth strategies by frontline health workers in developing countries: Systematic Review. Tropical Medicine and International Health, 20(8), 1003-1014. http://dx.doi.org/ doi:10.1111/tmi.12525.

23. Free, C., Phillips, G., Felix, L., Galli, L., Patel, V., Edwards, P. (2010). The effectiveness of M-Health technologies for improving health and health services: A systematic review protocol. BMC Research notes, 3, 1-26. http://dx.doi.org/ 10.1371/journal.pmed.1001363.

24. DeRenzi, B., Borriello, G., Jackson, J., et al. (2011). Mobile phone tools for fieldbased health care workers in low-income countries. Mount Sinai Journal of Medicine, 78, 406-418. http://dx.doi.org/ 10.1002/MSJ.

25. Surka, S., Edirippulige, S., Steyn, K., Gaziano, T., Puoane, T., Levitt, N. (2014). Evaluating the use of mobile phone technology to enhance cardiovascular disease screening by community health workers. International journal of medical informatics, 83(9), 648-654. http://dx.doi.org/10.1016/j.ijmedinf.2014.06.008. 
26. Poushter, J. (2016). Smartphone ownership and internet usage continues to climb in emerging economies. Retrieved from Pew Research Center website: www.pewresearch.org (accessed 7 February 2017).

27. Glascoe, F.P. (2013). Parents' Evaluation of Developmental Status (PEDS). Retrieved from www.pedstest.com (accessed 13 January 2017).

28. Brothers, K., Glascoe, F.P., Robertshaw, N. (2008). PEDS: Developmental Milestones- An accurate brief tool for surveillance and screening. Clinical Pediatrics, 47(3), 271-278.

29. Glascoe, F.P. (2013). Collaborating with parents: Using Parents' Evaluation of Developmental Status to detect and address developmental and behavioral problems. Nolensville, TN: PEDStest.com, LLC.

30. Statistics South Africa. (2012). Census 2011: Census in Brief. Pretoria, GP: Statistics South Africa.

31. Irwin, D., Pannbacker, M., Lass, N. (2008). Clinical research methods in SpeechLanguage Pathology and Audiology. San Diego: Plural Publishing, Inc.

32. De Vos, A.S., Strydom, H., Fouche, C.B., Delport, C. (2002). Research at grass roots: For the social sciences and human service professions. Pretoria, SA: Van Schaik Publishers.

33. Van der Linde, J., Swanepoel, D., Glascoe, F.P., Louw, E.M., Hugo, J., Vinck, B. (2015). Risks associated with communication delays in infants from underserved South African communities. African Journal of primary health care and family medicine, $7(1), 1-7$.

34. Chung, C.-Y., Liu, W.-Y., Chang, C.-J., Chen, C.-L., Tang, S.F.-T., Wong, A.M.K. (2011). The relationship between parental concerns and final diagnosis in 
children with developmental delay. Journal of Child Neurology, 26(4), 413-4. http://dx.doi.org/ 10.1177/0883073810381922.

35. Glascoe, F.P. (2005). Screening for developmental and behavioral problems. Mental Retardation and Developmental Disabilities, 11, 173-179. http://dx.doi.org/10.1002/mrdd.20068.

36. Currie, J. (2009). Healthy, wealthy and wise: Socioeconomic status, poor health in childhood, and human capital development. Journal of Economic Literature, 47(1), 87-122.

37. Duncan, G.J., Brooks-Gunn, J., Klebanov, P.K. (2017). Economic deprivation and early childhood development. Child development, 65(2), 296-318.

38. Walker, S.P., Wachs, T., Grantham-McGregor, S., et al. (2011). Inequality in early childhood: risk and protective factors for early childhood development. The Lancet, 378(9799), 1325-1338. http://dx.doi.org/10.1016/S0140-6736(11)605552.

39. Woolfenden, S., Eapen, V., Williams, K., Hayen, A., Spencer, N., Kemp, L. (2014). A systematic review of the prevalence of parental concerns measured by the Parents' Evaluation of Developmental Status (PEDS) indicating developmental risk. BMC Pediatrics, 14(231), 1-13. http://dx.doi.org/ 10.1186/1471-2431-14-231.

40. Scherzer, A.L., Chhagan, M., Kauchali, S., Susser, E. (2012). Global perspective on early diagnosis and intervention for children with developmental delays and disabilities. Developmental Medicine and Child Neurology, 54, 1079-1084. http://dx.doi.org/10.1111/j.1469-8749.2012.04348.x.

41. Hunter, L.R., Myszkowski, M.R., Johnson, S.K., Rostad, P.V., Weaver, A.L., Lynch, B.A. (2015). Comparing the clinical utility of the Infant Developmental 
Inventory with the Ages and Stages Questionnaire at 9-month well-child visits. Journal of Primary Care and Community Health, 6(3), 193-198.

42. Squires, J., Bricker, D. (2009). Ages and Stages Questionnaires. Third Edition. (ASQ-3): A parent-completed child-monitoring system. Baltimore, MD: Paul H Brookes.

43. Schoeman, J.C., Swanepoel, D., van der Linde, J. (2017). Developmental screening: predictors of follow-up adherence in primary healthcare. African Health Sciences, 17(1), 52-61. https://dx.doi.org/10.4314/ahs.v17i1.8.

44. Giannoni, P.P., Kass, P.H. (2010). Risk factors associated with children lost to care in a state early childhood intervention program. Research in Developmental Disabilities, 31, 914-923. http://dx.doi.org/10.1016/j.ridd.2010.02.013.

45. Chew-Graham, C., Burroughs, H., Hibbert, D., et al. (2014). Aiming to improve the quality of primary mental health care: developing an intervention for underserved communities. BMC Family Practice, 15(68), 1-19. http://dx.doi.org/10.1186/1471-2296-15-68.

46. Xaba, N.A., Peu, M.D., Phiri, S.S. (2012). Perceptions of registered nurses regarding factors influencing service delivery in expanding programmes in a primary healthcare setting. Health SA Gesondheid, 17(1), 1-12. http://dx.doi.org/10.4102/hsag.v17i1.535.

47. Braun, R., Catalani, C., Wimbush, J., Israelski, D. (2013). Community health workers and mobile technology: A systematic review of the literature. PloS one, 8(6), 1-7. http://dx.doi.org/10.1371/journal.pone.0065772.

48. Tulenko, K., Mogedal, S., Afzal, M.M., et al. (2013). Community health workers for universal health-care coverage: from fragmentation to synergy. Bulletin of the 
World Health $\quad$ Organization, $\quad 91(11), \quad$ 847-852. http://dx.doi.org/10.2471/BLT.13.118745.

49. Hussein, S.Y., Swanepoel, D., de Jager, L.B., Myburgh, H., Eikelboom, R., Hugo, J. (2015). Smartphone hearing screening in mHealth assisted community-based primary care. Journal of Telemedicine and Telecare, 22(7), 405-412.

50. Abrahams-Gessel, S., Denman, C.A., Montano, C., et al. (2015). The training and fieldwork experiences of community health workers conducting populationbased, noninvasive screening for CVD in LMIC. Global Heart, 10(1), 45-54. http://dx.doi.org/10.1016/j.gheart.2014.12.008. 


\section{DISCUSSION AND CONCLUSION}

Chapter aim: The aim of this chapter is to discuss and conclude the research findings. A critical evaluation of the research is conducted and recommendations for future research are documented.

\subsection{Discussion of Results}

Ten CCWs conducted community-based developmental screening within a period of 1 month through the use of mHealth-assisted technology. In addition to their regular workload, they screened 138 children within their community, with an average of ten children per day. This study is the first to explore the implementation and utility of mHealth developmental screening conducted by CCWs. It serves as a platform for using mHealth to conduct developmental screening in underserved communities.

\section{Referral rate}

The elevated overall referral rate of the PEDS tools (69\%) is likely attributable to this underserved populations' exposure to a range of environmental risk factors (Maleka et al., 2016; van der Linde, Swanepoel, Glascoe, Louw, Hugo, \& Vinck, 2015). Environmental risk factors identified indicating developmental delay include low household income, caregiver unemployment and households with more than three children (Chung et al., 2011; Currie, 2009; Duncan, Brooks-Gunn, \& Klebanov, 2017; Glascoe, 2005; Walker et al., 2011). Similar referral rates have been reported in other studies conducted in underserved communities (Maleka et al., 2016; van der Linde, Swanepoel, Glascoe, Louw, Hugo et al., 2015). Yet, the global referral rate reported in a recent systematic review, was lower (34\%) (Woolfenden et al., 2014) than the rate in the current study. However, it should be taken into account that most of these studies were conducted in high-income countries. LMIC such as South Africa that have a higher burden of disease, such as HIV/AIDS, tuberculosis and higher child mortality rates (Mayosi \& Benatar, 2014), have a higher prevalence of developmental delays.

Risk exposure and its cumulative effect on vulnerable populations advocates the need for developmental screening to improve early detection of developmental delays (Glascoe, 2005). This should decrease the age of identification in children being unidentified at a younger age (Scherzer, Chhagan, Kauchali, \& Susser, 2012). 
A clear discrepancy exists when comparing screen referral rates of the PEDS tools within the two age categories (48\% for the younger age group compared to $82 \%$ ). This may be indicative of the cumulative effect of limited access to quality developmental services on older children. Multiple studies found similar results, reiterating the necessity of early detection programmes for children raised in underserved communities (Halle et al., 2009; Lehr et al., 2016; Samuels et al., 2012; Valla, WentzelLarsen, T., Hofoss, D., \& Slinning, 2015). Previous studies reported on the visible increase in older children accurately identified with developmental delays (Chung et al., 2011; Lehr et al., 2016).This emphasises the need for services aiding in early identification of children, below 38 months, at increased risk for developmental delays, before the developmental gap widens.

Although not significant ( $p>0.05$; Chi-Square), the PEDS:DM overall referral rate $(68 \%)$ was higher than the PEDS overall referral rate (40\%). Parental lack of knowledge regarding different developmental domains may result in parents being unconcerned and unaware about possible developmental risks (Glascoe, 2013a). Several studies found similar results (Glascoe, 2013a; Woolfenden et al., 2014), indicating the necessity of including a milestone-focused measure as part of a screening protocol, so as to discern delays that caregivers may not have identified (Glascoe, 2013a). This supports the approach of using both the PEDS and PEDS:DM in combination when screening children from high-risk populations.

The significantly lower referral rate of the PEDS rescreen $(27 \%)$ compared to the PEDS screen (35\%) may be ascribed to the possible elimination of false positives (Hodges, Landin, Nugent, \& Simpson, 2016). This warrants the need to closely monitor these children to prevent possible under referrals, but also to ensure that only true cases of concern are identified. Previous studies also found screen rates to be significantly higher (Glascoe, 2013a). Contradictory to this, other research studies indicated that caregivers with low socio-economic status (SES) are more likely to raise concerns only when a second screen is conducted (Glascoe, 2013a). It also indicated that parents' concerns should be elicited systematically (Glascoe, 2013a), allowing parents to closely monitor their child's development before a second screen is conducted, to ensure that only true concerns are recorded with the rescreen. 


\section{Test duration}

Test times, for both the screen and rescreen (mean 12.5 minutes), agree with the reported administration time of the paper-based PEDS tool (Chung et al., 2011). No previous studies have reported on the screening duration when using the PEDS application. Older CCWs took significantly longer $(p<0.05)$ to conduct the screening than their younger counterparts. This is likely partly a function of younger CCWs being more accustomed to smartphone technology. Screenings using mHealth may thus be implemented quicker by younger CCWs. Older CCWs may need more time and training to become more accustomed to smartphone technology. Another study conducted in PHC settings reported screening times using paper-based instruments completed by CCWs that took an average of five minutes longer than in the current study (Hunter et al., 2015; Squires \& Bricker, 2009). This suggests that the mHealth tool was time-efficient and effectively implemented by the trained CCWs in the current study.

\section{CCWs' perceptions}

CCWs completed the mHealth screening process within a period of one month (average of 10 children per day). Most children (89\%) identified with concerns were rescreened within 14 days. Developmental screening administered by CCWs in the home setting has shown to have a positive impact on follow-up adherence for rescreen. Transportation costs can impede attendance to PHC facilities (Schoeman, Swanepoel, \& van der Linde, 2017). However, mHealth allows for the screen to take place at home, where only the caregiver is relied upon being present for the screening. Thus, children do not have to be taken out of their educational setting to be screened. Studies reported poor follow-up adherence of high risk families to PHC settings primarily due to logistical reasons and employment responsibilities (Giannoni \& Kass, 2010; Schoeman et al., 2017). For this reason, mHealth screening in the home-setting may be an adequate model for service delivery in terms of early detection and close developmental surveillance.

CCWs (100\%) reported that the training, to use and implement the screening application, was adequate and the application was easy to comprehend (90\%). The screening programme also appears to contribute to the knowledge of community members, which includes CCWs (Braun, Catalani, Wimbush, \& Israelski, 2013; 
Tulenko et al., 2013), by increasing awareness whilst developmental screening takes place. Almost all CCWs (90\%) reported that caregivers agreed with the screening results. Over a third of the CCWs highlighted the need to educate the community regarding the importance of developmental screening (38\%).

CCWs indicated that they were motivated to promote increased developmental surveillance. A study reporting on the challenges perceived by healthcare professionals offering PHC services indicated limited time for training and service delivery (Chew-Graham et al., 2014), limited funds, lack of allocated space for services and shortages of nurses and PHC staff to conduct these services, leading to a lack in continuity of care (Xaba, Peu, \& Phiri, 2012). PHC personnel felt demotivated due to unrealistic workloads which compromise the quality of care provided (Xaba et al., 2012). CCWs using mHealth-assisted screening programmes for developmental surveillance may reduce the burden on PHC personnel.

Developmental screening for children older than 38 months was a future need identified by CCWs and caregivers in order to ensure early referral and improve future academic success.

\subsection{Clinical implications}

Evidence regarding technology and the use of mHealth in underserved communities is limited and inconsistent (Drury, 2005). This study provided insight regarding the use of mHealth to screen for children with developmental delays in underserved communities.

\section{CCW as providers of developmental screening services}

Evidence regarding the efficacy of CCWs that are not professionally trained in providing healthcare services is evolving, both locally and internationally (Braun et al., 2013). Results of this study demonstrate that CCWs may be key in addressing the needs of vulnerable populations in terms of early detection, by providing developmental screening in underserved communities. Results indicated that CCWs could successfully screen for developmental delays. CCWs may contribute to the education and knowledge of community members. Collaborating with CCWs to deliver these services can improve access to developmental screening and empower caregivers to monitor their children's development more closely, as well as alleviating 
the burden on healthcare professionals (Perry et al., 2016). This supports the concept of moving towards COPC (Hussein et al., 2015; van Pletzen, Zulliger, Moshabela, \& Schneider, 2014).

\section{mHealth-assisted service-delivery}

The study indicated the efficacy of CCWs using smartphone-based screening programmes to ultimately improve prevention and early detection of developmental delays within underserved communities. Smartphone technology is widely utilised and accepted as a means to provide appropriate health services to underserved communities (Fortuin et al., 2016). CCWs reported the mHealth screening programme to be easily understood, thus making it feasible for implementation by CCWs, regardless their age, qualification or education level.

Another benefit of using mHealth tools for developmental screening is the on-site capturing and sharing of data, allowing for instant results and immediate referral. The PEDS tools indicate to whom the child should be referred based on the concerns identified, where referral using checklists such as the RTHB were unclear. No followup appointment needs to be attended to give feedback regarding the results, hence allowing for easily administered, time efficient developmental screening. In some cases, when multiple developmental domains were identified as being a concern, the PEDS tools did not indicate the professional to whom the child should be referred. This should be addressed for successful, effortless use of the PEDS tools in future. This will clarify the line from referral by CCWs to diagnostic evaluations by healthcare professionals.

\subsection{Critical evaluation}

A critical evaluation is necessary in order to evaluate the study in terms of its strengths and limitations.

\section{Strengths of the study}

To the best of the researcher's knowledge, this is the first study to date to report on the clinical utility of a community-based developmental screening programme through the use of mHealth technology. The study demonstrated the benefits of implementing developmental screening services when conducted by CCWs. This study has high 
ecological validity, since the study was conducted in a representative community with current CCWs already part of an NGO. Furthermore, it revealed the potential for the successful implementation of such a screening programme in underserved communities, particularly when in collaboration with established CCWs who serve in these communities. Data extraction could occur weekly during scheduled meetings at the NGO satellite office, ensuring effortless, quick data transfer. The current study may serve as a platform for future implementation of other CCW-driven mHealth developmental screening programmes. Additionally, this study identifies and addresses the many barriers faced by PHC facilities and the community members they serve. This research proposed a viable screening programme that is sustainable in the long term.

\section{Limitations of the study}

Four limitations were identified. Firstly, the small sample of CCWs $(n=10)$ that participated in the study limited the sample size of the families, thus restricting the amount of screens done per day. Secondly, the accuracy of the screening could not be determined as no gold standard was used to validate the results. Another limitation of the study is the possible inaccurate representation of test duration. Test duration is recorded from the moment the application is opened and only stops when the 'Finish' button is pressed, which may ultimately lead to the inaccurate reporting of actual developmental screening test times. This may occur as CCWs talk to the caregivers and explain unclear questions while the screening is in progress. Lastly, some families were not home at the time of rescreening, leading to identified children not being rescreened and possibly not being referred for a comprehensive evaluation from a healthcare professional.

\subsection{Future research}

The study highlights the potential for future research studies. Future research should focus on identifying older children who were not included in the current study, to ensure that these children, who tend to have larger developmental gaps, are identified timeously. Screening programmes that are conducted in home-based contexts should be compared to programmes conducted in PHC settings within the same community. This will give a more accurate description of its clinical utility and efficiency. Furthermore, the screening results obtained should be validated against a gold 
standard diagnostic evaluation tool, such as the Bayley Scales of Infant and Toddler Development (Bayley-III), Third Edition (Bayley, 2006). This may assist in the accurate identification of developmental delays in paediatric populations. Future research should be aimed at determining the adherence of caregivers attending the diagnostic evaluations scheduled after children were identified by the PEDS tools screening programme.

Future studies can be conducted to describe the perceptions of the caregivers before and after conducting developmental screening. Thus, establishing whether caregiver knowledge has improved regarding developmental screening and surveillance, as well as developmental milestones. This can be piloted through the use of surveys before and after a developmental screening awareness campaign. Research should be conducted to clarify the different roles of CHWs and CCWs, especially in South Africa, as no clear discrepancy exists.

\subsection{Conclusion}

Developmental screening programmes conducted by CCWs in community-based settings are innovative approaches to the timely identification of children with possible developmental delays. Several studies have reported the effectiveness of CHWs in conducting mHealth screening programmes (Abrahams-Gessel et al., 2015; Agarwal, Perry, long, \& Labrique, 2015; Hussein et al., 2015; Maleka et al., 2016; Squires \& Bricker, 2009; Surka et al., 2014). This study demonstrates the potential of CCWs to use mHealth tools to reduce the demand on overburdened health professionals in typical healthcare settings. Additionally, several areas for future research were identified during the implementation of the developmental screening programme, especially in terms of developmental screening in the home vs at a PHC facility. Findings indicate that many children can be screened in a short period of time, resulting in early and accurate referral to the appropriate healthcare professionals. mHealth screening programmes can improve universal access to developmental screening and surveillance by bringing services into the homes of vulnerable populations through minimally trained persons. 


\section{REFERENCES}

Abrahams-Gessel, S., Denman, C. A., Montano, C. M., Gaziano, T., Levitt, N., RiveraAndrade, A.,... Puoane, T. (2015). The training and fieldwork experiences of community health workers conducting population-based, noninvasive screening for CVD in LMIC. Global Heart, 10(1), 45-54. https://doi.org/10.1016/j.gheart.2014.12.008

Agarwal, S., Perry, H. B., long, L., \& Labrique, A. B. (2015). Evidence on feasibility and effective use of mHealth strategies by frontline health workers in developing countries: Systematic review. Tropical Medicine and International Health, 20(8), 10031014. https://doi.org/10.1111/tmi.12525

Austin-Evelyn, K., Rabkin, M., Macheka, T., Mutiti, A., Mwansa-Kambafwile, J., Dlamini, T., \& El-Sadr, W. M. (2017). Community health worker perspectives on a new primary health care initiative in the Eastern Cape of South Africa. PloS one, 12(3), 113. https://doi.org/10.1371/journal.pone.0173863

Awases, M. H., Bezuidenhout, M. C., \& Roos, J. H. (2013). Factors affecting the performance of nurses in Namibia. Curationis, 36(1), 1-8. https://doi.org/10.4102/ curationis.v36i1.108

Bam, N., Marcus, T., Hugo, J., \& Kinkel, H.-F. (2013). Conceptualizing Community Oriented Primary Care (COPC) - the Tshwane, South Africa, health post model. African Journal of Primary Health Care \& Family Medicine, 5(1), 1-3. https://doi.org/10.4102/phcfm.v5i1.423

Barron, P., \& Padarath, A. (2017). Twenty years of the South African health review. Durban, South Africa.

Bayley, N. (2006). Bayley Scales of Infant and Toddler Development-Third Edition. San Antonio, TX: Harcourt Assessment.

Ben-Zeev, D., Schueller, S. M., Begale, M., Duffecy, J., Kane, J. M., \& Mohr, D. C. (2015). Strategies for mHealth research: lessons from 3 mobile intervention studies. Adm Policy Ment Health, 42, 157-167. https://doi.org/10.1007/s10488-014-0556-2 
Boogerd, E. A., Arts, T., Engelen, L., \& van de Belt, T. (2015). "What is eHealth": Time for an update? JMIR Res Protoc, 4(1), e29. https://doi.org/10.2196/resprot.4065

Boyle, C. A., Boulet, S., Schieve, L. A., Cohen, R. A., Blumberg, S. J., Yeargin-Allsopp, M.,. . Kogan, M. D. (2011). Trends in the prevalence of developmental disabilities in US children, 1997-2008. Pediatrics, 127(6), 1034-1042. https://doi.org/10.1542/peds.2010-2989

Braun, R., Catalani, C., Wimbush, J., \& Israelski, D. (2013). Community Health Workers and Mobile Technology: A Systematic Review of the Literature. PloS one, 8(6), 1-7. https://doi.org/10.1542/peds.2012-3313

Brothers, K., Glascoe, F. P., \& Robertshaw, N. (2008). PEDS: Developmental milestones- an accurate brief tool for surveillance and screening. Clinical Pediatrics, 47(3), 271-278. https://doi.org/10.1177/0009922807309419

Brownstein, J. N., Hirsch, G. R., Rosenthal, E. L., \& Rush, C. H. (2011). Community health workers " 101 " for primary care providers and other stakeholders in health care systems. The Journal of ambulatory care management, 34(3), 210-220. https://doi.org/10.1097/JAC.0b013e31821c645d

Catwell, L., \& Sheikh, A. (2009). Evaluating eHealth interventions: The need for continuous systemic evaluation. PLoS medicine, 6(8), e1000126. https://doi.org/10.1371/journal.pmed.1000126

Chew-Graham, C., Burroughs, H., Hibbert, D., Gask, L., Beatty, S., Gravenhorst, K.,. . . Dowrick, C. (2014). Aiming to improve the quality of primary mental health care: Developing an intervention for underserved communities. BMC family practice, 15, 68. https://doi.org/10.1186/1471-2296-15-68

Chung, C.-Y., Liu, W.-Y., Chang, C.-J., Chen, C.-L., Tang, S. F.-T., \& Wong, A. M.-K. (2011). The relationship between parental concerns and final diagnosis in children with developmental delay. Journal of child neurology, 26(4), 413-419. https://doi.org/10.1177/0883073810381922

Cloete, I., Daniels, L., Jordaan, J., Derbyshire, C., Volmink, L., \& Schubl, C. (2013). Knowledge and perceptions of nursing staff on the new Road to Health Booklet growth 
charts in primary healthcare clinics in the Tygerberg subdistrict of the Cape Town metropole district. South African Journal of Clinical Nutrition, 26(3), 141-146.

Coovadia, H., Jewkes, R., Barron, P., Sanders, D., \& Mclntyre, D. (2009). The health and health system of South Africa: historical roots of current public health challenges. Lancet, 374, 817-834. https://doi.org/10.1016/S0140-

Cullinan, K. (2006). Health services in South-Africa: A basic introduction. Retrieved from www.health-e.org.za

Currie, J. (2009). Heallthy, wealthy and wise: Socioeconomic status, poor health in childhood, and human capital development. Journal of Economic Literature, 47(1), 87122. https://doi.org/10.1257/jel.47.1.87

Delany, A., Jehoma, S., \& Lake, L. (2016). South African Child Gauge 2016. Children's Institute, University of Cape Town, Cape Town.

Delobelle, P., Rawlinson, J. L., Ntuli, S., Malatsi, I., Decock, R., \& Depoorter, A. M. (2011). Job satisfaction and turnover intent of primary healthcare nurses in rural South Africa: a questionnaire survey. Journal of Advanced Nursing, 67(2), 371-383. https://doi.org/10.1111/j.1365-2648.2010.05496.x

DeRenzi, B., Borriello, G., Jackson, J., Kumar, V., Parikh, T., Pushwaz, V., \& Lesh, N. (2011). Mobile phone tools for field-based health care workers in low-income countries. Mount Sinai Journal of Medicine, 78, 406-418. https://doi.org/10.1002/msj.20256

deVos, A. S., Strydom, H., Fouche, C. B., \& Delport, C. (2002). Research at Grass Roots: For the social sciences and human service professions (2nd ed.). Pretoria, South Africa: Van Schaik Publishers.

Donald, K., Hall, D., \& Dawes, A. (Eds.). (2012). Early Child Development and Detection in South Africa. Nolensville, Tennessee.

Drury, P. (2005). eHealth: A model for developing countries. eHealth International Journal, 19-26. 
Duncan, G. J., Brooks-Gunn, J., \& Klebanov, P. K. (2017). Economic deprivation and early childhood development. Child Development, 65(2), 296-318.

Fortuin, J., Salie, F., Abdullahi, L. H., \& Douglas, T. S. (2016). The impact of mHealth interventions on health systems: a systematic review protocol. Systematic Reviews, 5(200), 1-6. https://doi.org/10.1186/s13643-016-0387-1

Free, C., Phillips, G., Felix, L., Galli, L., Patel, V., \& Edwards, P. (2010). The effectiveness of M-health technologies for improving health and health services: $A$ systematic review protocol. BMC research notes, 3, 1-26. https://doi.org/10.1186/1756-0500-3-250

Friedman, I., Ramalepa, M., Matjuis, F., Bhengu, L., Lloyd, B., Mafuleka, A., \& Ndaba, L., Boloyi, B. (2007). Moving towards best practice: documenting and learning from existing community health/care worker programmes. Durban: Health Systems Trust.

Giannoni, P. P., \& Kass, P. H. (2010). Risk factors associated with children lost to care in a state early childhood intervention program. Research in Developmental Disabilities, 31, 914-923. https://doi.org/10.1016/j.ridd.2010.02.013

Glascoe, F. P. (2005). Screening for developmental and behavioral problems. Mental Retardation and Developmental Disabilities Research Reviews, 11, 173-179. https://doi.org/10.1002/mrdd.20068

Glascoe, F. P. (2013a). Collaborating with parents: Using Parents' Evaluation of Developmental Status to detect and address developmental and behavioral problems (2nd ed.). Nolensville, TN: PEDStest.com, LLC.

Glascoe, F. P. (2013b). Parents' Evaluation of Developmental Status (PEDS). Retrieved from www.pedstest.com

Gopalan, S. S., Mohanty, S., \& Das, A. (2012). Assessing community health workers' performance motivation: A mixed-methods approach on India's Accredited Social Health Activists (ASHA) programme. BMJ open, 2(5), 1-10. https://doi.org/10.1136/bmjopen-2012-001557 
Halle, T., Forry, N., Hair, E., Perper, K., Wandner, L., Wessel, J., \& Vick, J. (2009). Disparities in Early Learning and Development: Lessons from the Early Childhood Longitudinal Study - Birth Cohort (ECLS-B). Washington, DC.

Health Systems Trust. (2012). National Health Care Facilities Baseline Audit: National Summary Report. Westville, Durban.

Hodges, K. L., Landin, M. D., Nugent, M. L., \& Simpson, P. M. (2016). Early Developmental Screening for Children in Foster Care. Journal of Child and Family Studies, 25(7), 2155-2163. https://doi.org/10.1007/s10826-016-0397-6

Hunter, J. R., Asmall, S., Ravhengani, N. M., Chandran, T. M., Tucker, J., \& Mokgalagadi, Y. (2017). The ideal clinic in South Africa: progress and challenges in implementation. Durban, South Africa.

Hunter, L. R., Myszkowski, M. R., Johnson, S. K., Rostad, P. V., Weaver, A. L., \& Lynch, B. A. (2015). Comparing the clinical utility of the Infant Developmental Inventory with the Ages and Stages Questionnaire at 9-month well-child visits. Journal of Primary Care and Community Health, 6(3), 193-198.

Hussein, S., Swanepoel, D. W., Jager, L. de, Myburgh, H., Eikelboom, R., \& Hugo, J. (2015). Smartphone hearing screening in mHealth assisted community-based primary care. Journal of Telemedicine and Telecare, 22(7), 405-412. https://doi.org/10.1177/1357633X15610721

Irwin, D., Pannbacker, M., \& Lass, N. (2008). Clinical Research Methods in SpeechLanguage Pathology and Audiology. San Diego: Plural Publishing, Inc.

Johnson, S., \& Gunn, V. (2015). Community health workers as a component of the healthcare team. Pediatric Clinics of North America, 62(5), 1313-1328. https://doi.org/10.1016/j.pcl.2015.06.004

Kelly, Y., Sacker, A., Schoon, I., \& Nazroo, J. (2006). Ethnic differences in achievement of developmental milestones by 9 months of age: the millenium cohort study. Developmental Medicine and Child Neurology, 48, 825-830. https://doi.org/10.1017/S0012162206001770 
Kyarkanaye, T., Dada, S., \& Samuels, A. (2017). Collaboration in early childhood intervention services in Gauteng: Caregiver perspectives. Infants \& Young Children, 30(3), 238-254. https://doi.org/10.1097/IYC.0000000000000095

Leedy, P., \& Ormrod, J. (2015). Practical Research: Planning and Design (11th ed.). Harlow, England: Pearson.

Lehmann, U., van Damme, W., Barten, F., \& Sanders, D. (2009). Task shifting: the answer to the human resources crisis in Africa? Human Resources for Health, 7(49), 1-4. https://doi.org/10.1186/1478-4491-7-49

Lehr, M., Wecksell, B., Nahum, L., Neuhaus, D., Teel, K. S., Linares, L. O., \& Diaz, A. (2016). Parenting stress, child characteristics, and developmental delay from birth to age five in teen mother-child dyads. Journal of Child and Family Studies, 25, 10351043. https://doi.org/10.1007/s10826-015-0282-8

Lipkin, P. (2009). Motor development and dysfunction. Developmental-Behavioral Pediatrics, 4, 643-652. https://doi.org/10.1016/B978-1-4160-3370-7.00066-3

Liu, A., Sullivan, S., Khan, M., Sachs, S., \& Singh, P. (2011). Community health workers in global health: scale and scalability. Mount Sinai Journal of Medicine, 78, 419-435. https://doi.org/10.1002/msj.20260

Maleka, B. K., van der Linde, J., Glascoe, F. P., \& Swanepoel, D. W. (2016). Developmental screening-evaluation of an $\mathrm{m}$-Health version of the Parents Evaluation Developmental Status tools. Telemedicine journal and e-health : the official journal of the American Telemedicine Association, 22(12), 1013-1018. https://doi.org/10.1089/tmj.2016.0007

Maxwell, D., \& Satake, E. (2006). Research amd Statistical Methods in Communication Sciences and Disorders. Boston: Thomson: Delmar Learning.

Mayosi, B., \& Benatar, S. (2014). Health and healthcare in South Africa- 20 years after Mandela. The New England Journal of Medicine, 371(14), 1344-1353. https://doi.org/10.1056/NEJMsr1405012 
Moshabela, M., Sips, I., \& Barten, F. (2015). Needs assessment for home-based care and the strengthening of social support networks: the role of community care workers in rural South Africa. Global Health Action, 8(1), 29265. https://doi.org/10.3402/gha.v8.29265

Neupane, S., Odendaal, W., Friedman, I., Jassat, W., Schneider, H., \& Doherty, T. (2014). Comparing a paper based monitoring and evaluation system to a mHealth system to support the national community health worker programme, South Africa: an evaluation. BMC Medical Informatics and Decision Making, 14(69), 1-9. https://doi.org/10.1186/1472-6947-14-69

O'Brien, M. J., Squires, A. P., Bixby, R. A., \& Larson, S. C. (2009). Role development of community health workers: an examination of selection and training processes in the intervention literature. American journal of preventive medicine, 37(6 Suppl 1), S262-9. https://doi.org/10.1016/j.amepre.2009.08.011

Okeyo, I., \& Dowse, R. (2016). Community care worker perceptions of their roles in tuberculosis care and their information needs. Health SA Gesondheid, 21, 245-252. https://doi.org/10.1016/j.hsag.2016.05.004

Olaniran, A., Smith, H., Unkels, R., Bar-Zeev, S., van den Broek, N., Olaniran, A.,. . . van den Broek, N. (2017). Who is a community health worker? - a systematic review of definitions. Global Health Action, 10(1), 1272223. https://doi.org/10.1080/16549716.2017.1272223

Perry, H. B., Dhillon, R. S., Liu, A., Chitnis, K., Panjabi, R., Palazuelos, D.,... Nyenswah, T. (2016). Community health worker programmes after the 2013-2016 Ebola outbreak. Bulletin of the World Health Organization, 94(7), 551-553. https://doi.org/10.2471/BLT.15.164020

Poushter, J. (2016). Smartphone Ownership and Internet Usage Continues to Climb in Emerging Economies. Retrieved from Pew Research Center website: www.pewresearch.org 
Pratt, K., \& Mbaligontsi, M. (2014). Transactional analysis transforms community care workers in South Africa. Transactional Analysis Journal, 44(1), 53-67. https://doi.org/10.1177/0362153714531723

Robson, C. (2011). Real world research (3rd ed.). Chichester, United Kingdom: Wiley.

Samuels, A., Slemming, W., \& Balton, S. (2012). Early childhood intervention in South Africa in relation to the developmental systems model. Infants \& Young Children, 25(4), 334-345. https://doi.org/10.1097/IYC.0b013e3182673e12

SASLHA. (2011). Principles of ethics. Pretoria, South Africa.

Scherzer, A. L., Chhagan, M., Kauchali, S., \& Susser, E. (2012). Global perspective on early diagnosis and intervention for children with developmental delays and disabilities. Developmental Medicine and Child Neurology, 54, 1079-1084. https://doi.org/10.1111/j.1469-8749.2012.04348.x

Schneider, H., Hlophe, H., \& van Rensburg, D. (2008). Community health workers and the response to HIV/AIDS in South Africa: Tensions and prospects. Health policy and planning, 23(3), 179-187. https://doi.org/10.1093/heapol/czn006

Schoeman, J. C., Swanepoel, D. W., \& van der Linde, J. (2017). Developmental screening: predictors of follow-up adherence in primary healthcare. African health sciences, 17(1), 52-61. https://doi.org/10.4314/ahs.v17i1.8

Schonwald, A., Huntington, N., Chan, E., Risko, W., \& Bridgemohan, C. (2009). Routine Developmental Screening Implemented in Urban Primary care settings: more evidence of feasibility and effectiveness. Pediatrics, 123(2), 660-668. https://doi.org/10.1542/peds.2007-2798

Singh, P., \& Sachs, J. D. (2013). 1 million community health workers in sub-Saharan Africa by 2015. Lancet, 382(9889), 363-365. https://doi.org/10.1016/S0140$6736(12) 62002-9$

Sips, I., Mazanderani, A. H., Schneider, H., Greeff, M., Barten, F., \& Moshabela, M. (2014). Community care workers, poor referral networks and consumption of personal 
resources in rural South Africa. PloS one, 9(4), 995324. https://doi.org/10.1371/journal.pone.0095324

Smith, T. (2016). Developemntal surveillance and screening and the electronic health record. Pediatric Clinics of North America, 63(5), 933-943. https://doi.org/10.1016/j.pcl.2016.06.014

South African Nursing Council. (2017). Provincial distribution of nursing manpower versus the population of South Africa. Retrieved from www.sanc.co.za/stats.htm

Squires, J., \& Bricker, D. (2009). Ages and Stages Questionnaires. Third Edition. (ASQ-3): A parent-completed child-monitoring system. Baltimore, MD: Paul H Brookes.

Statistics South Africa. (2011). Census 2011: Census in Brief. Pretoria.

Surka, S., Edirippulige, S., Steyn, K., Gaziano, T., Puoane, T., \& Levitt, N. (2014). Evaluating the use of mobile phone technology to enhance cardiovascular disease screening by community health workers. International journal of medical informatics, 83(9), 648-654. https://doi.org/10.1016/j.ijmedinf.2014.06.008

Tulenko, K., Mogedal, S., Afzal, M. M., Frymus, D., Oshin, A., Pate, M.,. . . Zodpey, S. (2013). Community health workers for universal health-care coverage: From fragmentation to synergy. Bulletin of the World Health Organization, 91(11), 847-852. https://doi.org/10.2471/BLT.13.118745

U.S. Bureau of Labor Statistics. (2017). Standard Occupation Classification. Retrieved from https://www.bls.gov/soc/\#revision

Valla, L., Wentzel-Larsen, T., Hofoss, D., \& Slinning, K. (2015). Prevalence of suspected developmental delays in early infancy: results from a regional populationbased longitudinal study. BMC Pediatrics, 15(215), 1-8. https://doi.org/10.1186/s12887-015-0528-z

van der Linde, J., Kritzinger, A., \& Redelinghuys, A. (2009). The identification process in early communication intervention followed by primary health care personnel In 
Ditsobotla sub-district. The South African Journal of Communication Disorders, 56, 48-59.

van der Linde, J., Swanepoel, D. W., Glascoe, F. P., Louw, E. M., Hugo, J., \& Vinck, B. (2015). Risks associated with communication delays in infants from underserved South African communities. African journal of primary health care \& family medicine, 7(1), 1-7. https://doi.org/10.4102/PHCFM.V7I1.841

van der Linde, J., Swanepoel, D. W., Glascoe, F. P., Louw, E. M., \& Vinck, B. (2015). Developmental screening in South Africa: Comparing the national developmental checklist to a standardized tool. African health sciences, 15(1), 188-196. https://doi.org/10.4314/ahs.v15i1.25

van der Linde, J., Swanepoel, D. W., Hanekom, L., Lemmer, T., Schoeman, K., Glascoe, F. P., \& Vinck, B. (2016). Early detection of communication delays with the PEDS tools in at-risk South African infants. African Journal of Disability, 5(1), a223a227. https://doi.org/10.4102/ajod.v5i1.223

van der Merwe, M., Cilliers, M., Mare, C., van der Linde, J., \& Le Roux, M. (2017). Evaluation of a Zulu translation of the Parents' Evaluation of Developmental Status. African Journal of Primary Health Care \& Family Medicine, 9(1), 1-6. https://doi.org/10.4102/phcfm.v9i1.1365

van Pletzen, E., Zulliger, R., Moshabela, M., \& Schneider, H. (2014). The size, characteristics and partnership networks of the health-related non-profit sector in three regions of South Africa: implications of changing primary health care policy for community-based care. Health policy and planning, 29, 742-752. https://doi.org/10.1093/heapol/czt058

Walker, S. P., Wachs, T., Grantham-McGregor, S., Black, M. M., Nelson, C. A., Huffman, S. L.,. . . Richter, L. (2011). Inequality in early childhood: risk and protective factors for early child development. The Lancet, 378(9799), 1325-1338. https://doi.org/10.1016/S0140

Woolfenden, S., Eapen, V., Williams, K., Hayen, A., Spencer, N., \& Kemp, L. (2014). A systematic review of the prevalence of parental concerns measured by the Parents' 
Evaluation of Developmental Status (PEDS) indicating developmental risk. BMC Pediatrics, 14(231), 1-13. https://doi.org/10.1186/1471-2431-14-231

World Health Organization. (2015). Strengthening the capacity of community health workers to deliver care for sexual, reproductive, maternal, newborn, child and adolescent health. Geneva, Switzerland.

Xaba, N. A., Peu, M. D., \& Phiri, S. S. (2012). Perceptions of registered nurses regarding factors influencing service delivery in expanding programmes in a primary healthcare setting. Health SA Gesondheid, 17(1), 1-12. https://doi.org/10.4102/hsag.v17i1.535 
6. APPENDICES 
APPENDIX A: ETHICAL CLEARANCE: FACULTY OF HUMANITIES, UNIVERSITY OF PRETORIA 
Faculty of Humanities Research Ethics Committee

21 April 2017

Dear Ms van der Merwe

Project: $\quad$ Early detection of developmental delays in vulnerable children by community health workers: an mHealth service

Researcher: delivery model

Supervisor: MN van der Merwe

Department: Ms $\mathrm{J}$ van der Linde

Reference number: Speech-Language Pathology and Audiology 12062482 (GW20170401HS)

Thank you for the application that was submitted for ethical consideration.

I have pleasure in informing you that the Research Ethics Committee formally approved the above study at an ad hoc meeting held on 20 April 2017. Data collection may therefore commence.

Please note that this approval is based on the assumption that the research will be carried out along the lines laid out in the proposal. Should your actual research depart significantly from the proposed research, it will be necessary to apply for a new research approval and ethical clearance.

We wish you success with the project.

Sincerely

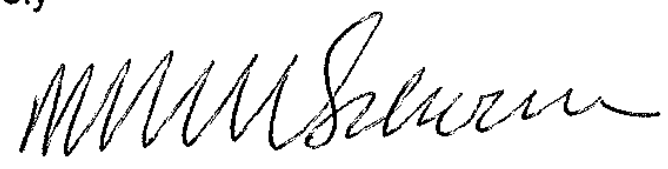

\section{Prof Maxi Schoeman}

Deputy Dean: Postgraduate and Research Ethics

Faculty of Humanities

UNIVERSITY OF PRETORIA

e-mail: tracey.andrew@up.ac.za

cc: Ms J van derLinde (Supervisor)

Prof B Vinck (HoD) 
APPENDIX B: REQUEST FOR COLLABORATION WITH FUTURE FAMILIES 
14 March 2017

Attention: Mrs. P. Learmonth

Executive Director

Future Families

Dear Mrs. Learmonth,

\section{Request to collaborate with Future Families in Mamelodi in a research study}

I, Maria van der Merwe, am a Masters degree student from the Department of Speech-Language Pathology and Audiology at the University of Pretoria. I will be conducting a research study titled "Early detection of developmental delays in vulnerable children by community health workers: An mHealth service delivery model". The main objective of my study is to evaluate the process of screening and follow-up in a community of vulnerable children where developmental delays are prevalent. A smartphone application will be used to conduct the screening.

We would like to request the community health care workers of Future Families to conduct developmental screening in Mamelodi using a smartphone application after receiving adequate one-onone training. The training will be provided by the researcher who is a qualified speech-language therapist.

Design and procedure: The community health workers working in Mamelodi will visit families in their homes to explain the screening process and the value of developmental screening. Once informed consent has been obtained from the caregiver, the community health workers will administer the screening test and assist the caregiver to complete a background information questionnaire. Additional biographical information will be obtained by the researcher from the Future Families database, should you permit us to do so. The child's primary caregiver will answer 16 questions regarding the child's development. A rescreen will be conducted should the initial screen produce a refer result. In the case that a refer result is obtained from both screens, a diagnostic assessment will be completed by the

University of Pretoria

PRETORIA 
researcher. The community health workers will also be requested to complete a short questionnaire to determine their acceptance of the feasibility of the screening process.

Participants: Community health workers will be trained to administer the PEDS application, a smartphone application used to screen for developmental delays. Parents or primary caregivers of children aged below three years, five months will be approached by their community health worker once the caregiver has given consent to participate in the study. Approximately 110 caregivers of children will be interviewed by the community health workers.

Ethical considerations: Ethical clearance will be obtained from the Faculty of Humanities at the University of Pretoria. All personal information obtained will be kept strictly confidential and the data collected will be used solely for research purposes.

Risk and benefits: There are no risks involved in participating in this study. However, the caregivers benefit from receiving feedback regarding their child's development based on their concerns, if necessary, their children will also be referred for a full diagnostic assessment. An additional benefit is that the Future Families' community health workers will be trained to screen and thus identify children with a developmental delay. The community health workers will be empowered to create awareness in their community about developmental delays and the importance of early detection and follow-up.

Confidentiality: All information obtained in this study will be kept strictly confidential. Should the data be reported in a scientific journal, no names or information which identifies the participants or community health workers will be included. Data will be stored securely on an electronic database and will be kept for a minimum of 15 years at the University of Pretoria, as stipulated by the university.

Please feel free to contact me or my research supervisors should you have any queries or further information. Thank you in advance.

Yours sincerely,

\section{thedellue \\ Maria van der Merwe \\ Student Researcher \\ Tel: 0768623579 \\ Email: mariav.vdmerwe@gmail.com}

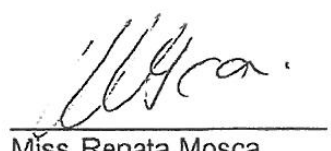

Miss Renata Mosca

Research Supervisor

Tel: 0124202814

Email: renata.mosca@up.ac.za

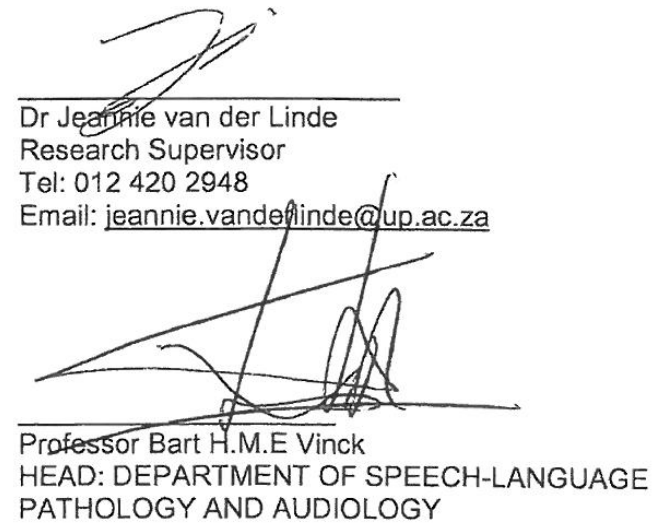




\section{Declaration of permission from the Executive Director of Future Families}

Herewith, I, Penclupe Learmak Executive Director of Future Families, grant permission to Maria van der Merwe to use the community health workers employed by Future Families for her study titled: Early detection of developmental delays in vulnerable children by community health workers: An mHealth service delivery model in Mamelodi. She is granted permission to train community health workers employed by Future Families to screen children in Mamelodi using the PEDS application. She is also granted permission to access the Future Families database to collect the biographical information of the participants. I have been informed regarding the type, procedure, risks and benefits of the research study.

I am fully aware that the data obtained will be used solely for the purpose of present and future research and may be presented in the format of a report, scientific article, lecture, conference or case study. It was explained to me that the participants' identities will at all times be kept confidential.

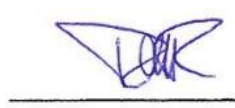

Mrs. P. Learmonth EXECUTIVE DIRECTOR: FUTURE FAMILIES

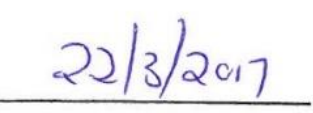

Date

\section{Future Families \\ NPO 084926 \\ Building $10 \mathrm{~A}$, CSIR}

Tel: (012) $8413159 / 3223$

Fax: (012) 8413228 
APPENDIX C: PARENT/CAREGIVER INFORMATION LEAFLET AND INFORMED CONSENT FORM 


\section{PARENT/CAREGIVER INFORMATION LEAFLET \& INFORMED CONSENT FORM}

Title of research study: Early detection of developmental delays in vulnerable children by community care workers using an mHealth tool

\section{INTRODUCTION}

As a parent/caregiver, you are invited to volunteer to participate in a research study. It is important to understand the purpose of the study. This leaflet contains information to answer all the questions you may have regarding the study. If you have any questions, please feel free to ask your community care worker. You may withdraw from the study at any point without any consequences to the services you and your child receive from Future Families.

\section{PURPOSE OF THE STUDY}

Developmental screening is important to make sure that early detection of developmental delays are noticed in time. However, healthcare services where screening is offered are limited and often inaccessible. Therefore, we have identified and trained community care workers in your community to screen your child at home using a smartphone application. The screening is quick to complete and only requires yes or no answers and short descriptions where necessary.

\section{DURATION OF THE STUDY}

If you decide to participate in this study, you will be requested to answer a few questions which will not take more than ten minutes of your time.

\section{EXPLANATION OF PROCEDURES TO BE FOLLOWED}

The study involves answering eight yes/no and two fill-in questions regarding your child's development and background information. A brief background information questionnaire will also be given to you to complete. Additional background information will be sourced from the Future Families database. The community worker will ask the questions and will provide support where necessary. If you have any concerns regarding your child's development; we will screen your child a second time. Any further concerns will be fully evaluated by a healthcare professional. The information collected during the screening process may be used for future research, if it is necessary.

\section{ETHICAL CLEARANCE}

This research study has been granted ethical clearance from the Faculty of Humanities at the University of Pretoria and permission has been obtained from Future Families.

\section{RIGHTS AS A PARTICIPANT}

Your and your child's participation in this study is entirely voluntary and should you wish to participate, are you allowed to stop at any time. If you decide to stop, the services you are currently receiving will not be affected in any way. Please note: It is essential that accurate information is provided in order for the necessary support to be offered to you and your child.

\section{RISKS AND BENEFITS INVOLVED}

There are no risks involved in participating in this study. However, the benefits are that you will receive information regarding your child's development based on your concerns and therefore, if necessary, you will be referred for specialised services. You will not be paid to take part in the study.

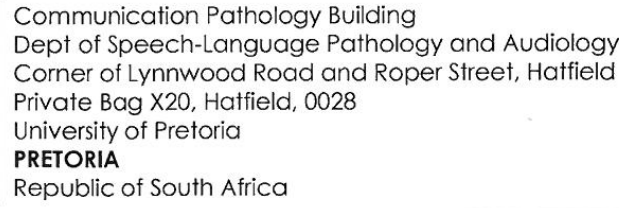




\section{CONFIDENTIALITY}

All information obtained in this study is strictly confidential. Should the data be reported in a scientific journal, no names or information that identify you or your child will be included. No personal details will be used and the results will be kept confidential, with only the researcher having access to the information. Information will be stored securely on an electronic database and will be kept for a minimum of 15 years at the University of Pretoria as the university requires. Your background information will be made available to the researcher by Future Families, but will be used for research purposes only and no personal information will be made available.

Please feel free to contact me or my research supervisors should you have any queries or further information. Thank you in advance.

Yours sincerely,
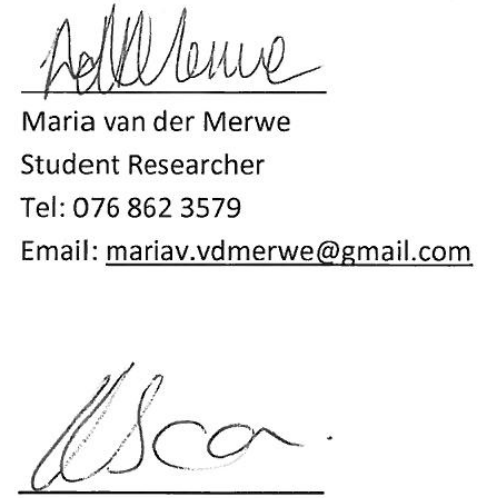

Miss Renata Mosca

Research Supervisor

Tel: 0124202814

Email: renata.mosca@up.ac.za

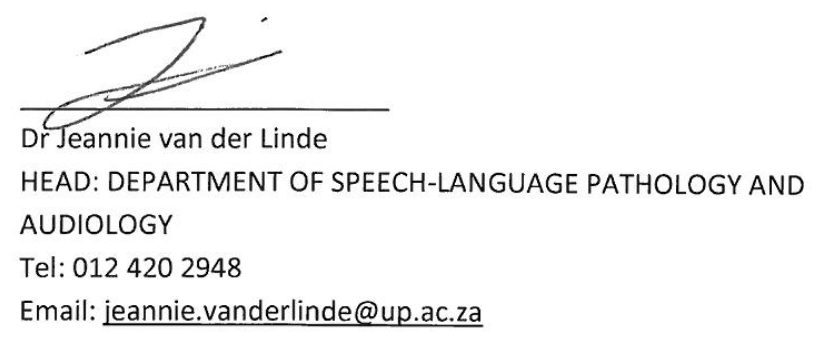

Tel: 0124202948

\section{INFORMED CONSENT FROM PARENT/CAREGIVER}

I, hereby confirm that I have been informed by the community health worker about the nature, conduct, risks and benefits of the research study titled: Early detection of developmental delays in vulnerable children by community care workers using an $\mathrm{mHealth}$ tool. I have also received, read and understood the information provided (Parent Information leaflet and informed consent) regarding the research study. Herewith, I give permission to the researcher to use the background information I provided to Future Families in order to complete the background information questionnaire.

I am aware that the results of the study, including my and my child's personal details including date of birth, initials and surname will be anonymously processed in a research report. I may, at any stage, without prejudice, withdraw my consent for my participation in the study. I have had sufficient opportunity to ask questions and (of my own free will) declare that I am prepared to participate in the study.

Please indicate whether you give permission that the information collected during the screening may be used for future research. 
Herewith, I give consent that the data obtained in the current research study may be used for future research, if necessary: (please tick relevant block)

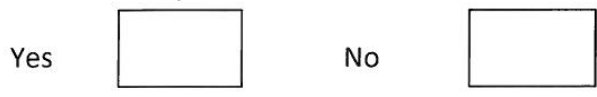

Parent/Guardian(s) name: (please print)

Child's name: (please print)

Community care worker's name: (please print)

Witness's name: (please print)

Witness's signature:

Date:

Parent/Guardian Signature

Community Care Worker Signature
Date

Date

\section{VERBAL PATIENT INFORMED CONSENT}

I, the undersigned, have read and have explained fully to the parent/caregiver, named , the patient information leaflet, which has indicated the nature and purpose of the research study titled: Early detection of developmental delays in vulnerable children by community care workers using an mHealth tool in which I have asked the parent/caregiver to participate. The explanation I have given has mentioned both the possible risks and benefits of the study. The parent/caregiver indicated that he/she understands that he/she will be free to withdraw from the study at any time for any reason.

Community care worker's name: (please print) 
APPENDIX D: COMMUNITY CARE WORKER INFORMATION LEAFLET AND INFORMED CONSENT FORM 


\section{COMMUNITY CARE WORKER INFORMATION LEAFLET \& INFORMED CONSENT FORM}

TITLE OF RESEARCH STUDY: Early detection of developmental delays in vulnerable children by community care workers using an mHealth tool

Dear community care worker,

\section{INTRODUCTION}

As a community care worker (CCW), you are invited to volunteer to participate in a research study. It is important to understand the purpose of the study. This leaflet contains information to answer all the questions you may have regarding the study. Should you have any queries, please feel free to ask the researcher (Maria van der Merwe).

\section{PURPOSE OF THE STUDY}

Developmental screening is crucial to ensure early detection of developmental delays. You as a CCW will be requested to conduct developmental screening in the Mamelodi community, using a smartphone application. An aim of this study is to determine your view and acceptance of this service delivery model.

\section{EXPLANATION OF PROCEDURES TO BE FOLLOWED}

The study involves developmental screening of young children. These services will be offered in the homes of caregivers with children who are supported by Future Families. The Parents' Evaluation of Developmental Status (PEDS) and Parents' Evaluation of Developmental Status: Developmental Milestones (PEDS: DM) has been converted into a smartphone application. This application will be used to screen the children by documenting the primary caregiver's concerns regarding their child's development. As a CCW working for Future Families, you will receive adequate training on how to explain the study to the caregivers and how to administer the developmental screening application. The researcher, who is a qualified speech-language therapist, will present the training at the weekly Friday meeting at the Ford Care Centre office in Mamelodi. The training will take about two hours.

During home visits, you as the CCW will be required to obtain informed consent, conduct the screening as well as explain the necessary information to the caregiver. You will also be required to collect some biographical information from the caregiver. The screening will take approximately ten minutes per caregiver, depending on their understanding and interpretation of the questions. Once the questions are completed the PEDS smartphone application will indicate whether the child "passed" or "referred" the screen. All children that refer from the initial screening should be rescreened within two weeks. A follow-up date should then be scheduled for the rescreen to take place.

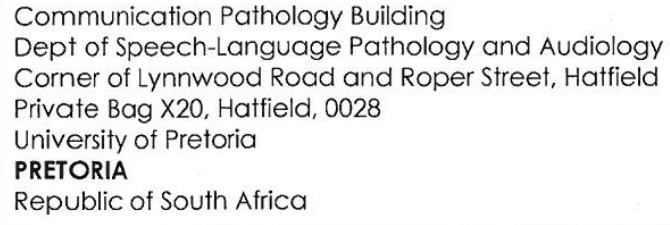


Once the initial screening and rescreening have taken place, each CCW will be asked to complete a short questionnaire regarding their perceptions of the screening process. The questionnaire will take approximately five minutes to complete.

\section{ETHICAL CLEARANCE}

This research study has been granted ethical clearance from the Faculty of Humanities at the University of Pretoria and permission has been obtained from Future Families. A copy of the approval letter can be arranged if necessary.

\section{RIGHTS AS A PARTICIPANT}

Your participation in this study is entirely voluntary and you are allowed to withdraw at any time, without any reason. Your withdrawal will not affect your role or participation as a CCW for Future Families in the Mamelodi community.

\section{RISKS AND BENEFITS INVOLVED}

There are no risks involved in participating in this study. The benefits are that you will receive training and information regarding the development and developmental milestones of children under 40 months. Your skills regarding the use of screening tools will also improve. You will be able to increase awareness in your community regarding developmental delays so that early detection and prevention can occur. You will be able to empower the caregivers in your community with knowledge about child development. No payment will be received for these services.

\section{CONFIDENTIALITY}

All information obtained in this study will be kept confidential. Should the data be reported in a scientific journal, no names or information which identifies you will be included. No personal details will be used and the results will be kept confidential. Data will be stored securely on an electronic database and will be kept for a minimum of 15 years at the University of Pretoria.

All CCWs will be requested to complete the questionnaire anonymously to ensure that opinions are given honestly. The results will be made available in the form of a report, upon request.

Please feel free to contact me or my research supervisors should you have any queries or further information. Thank you in advance.

Yours sincerely,

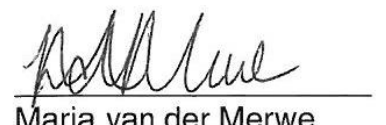

Student Researcher

Tel: 0768623579

Email: mariav.vdmerwe@gmail.com

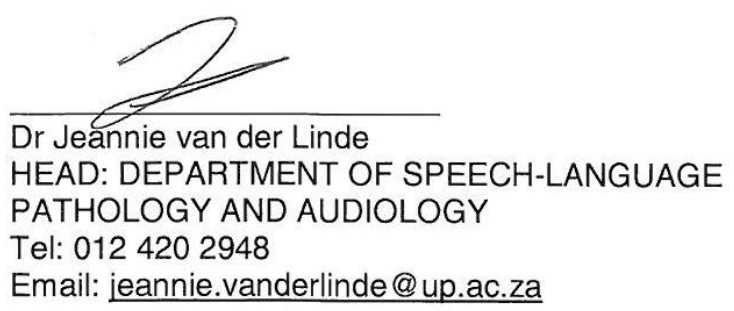

Email: jeannie.vanderlinde@up.ac.za

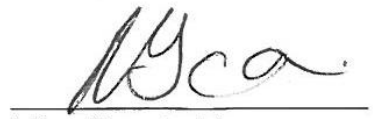

Miss Renata Mosca

Research Supervisor

Tel: 0124202814

Email: renata.mosca@up.ac.za 
CONSENT TO PARTICIPATE IN THE STUDY TITLED: "Early detection of developmental delays in vulnerable children by community care workers using an mHealth tool"

I, hereby confirm that I have been informed by the researcher, about the nature, conduct, risks and benefits of the research study. I have also received, read and understood the information provided (Information leaflet and informed consent) regarding the research study.

I am aware that the results of the study, including my personal details will be anonymously processed in a research report. I may, at any stage, without prejudice, withdraw my consent for my participation in the study. I have had sufficient opportunity to ask questions and (of my own free will) declare that I am prepared to participate in the study.

Please indicate whether you give permission that the data obtained may be used for future research.

Herewith, I give consent that the data obtained in the current research study may be used for future research, if necessary: (please tick relevant block)

Yes

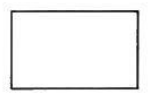

No

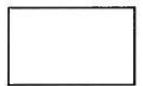

I have received a signed copy of this informed consent agreement.

Participant's name: (please print)

Participant's signature:

Date:

Researcher's name: (please print)

Researcher's signature:

Date:

Witness's name: (please print)

Witness's signature:

Date: 
APPENDIX E: CAREGIVER BACKGROUND INFORMATION QUESTIONNAIRE 


\section{Background information questionnaire}

Participant and family information (Van der Linde, Swanepoel, Glascoe, Louw, \& Vinck, 2015).

To be completed by the primary caregiver. All the information obtained in this questionnaire will be kept strictly confidential and will be used solely for research purposes.

Please answer the questions by drawing a circle around the appropriate number in a shaded box or by writing your answer in the shaded box provided.

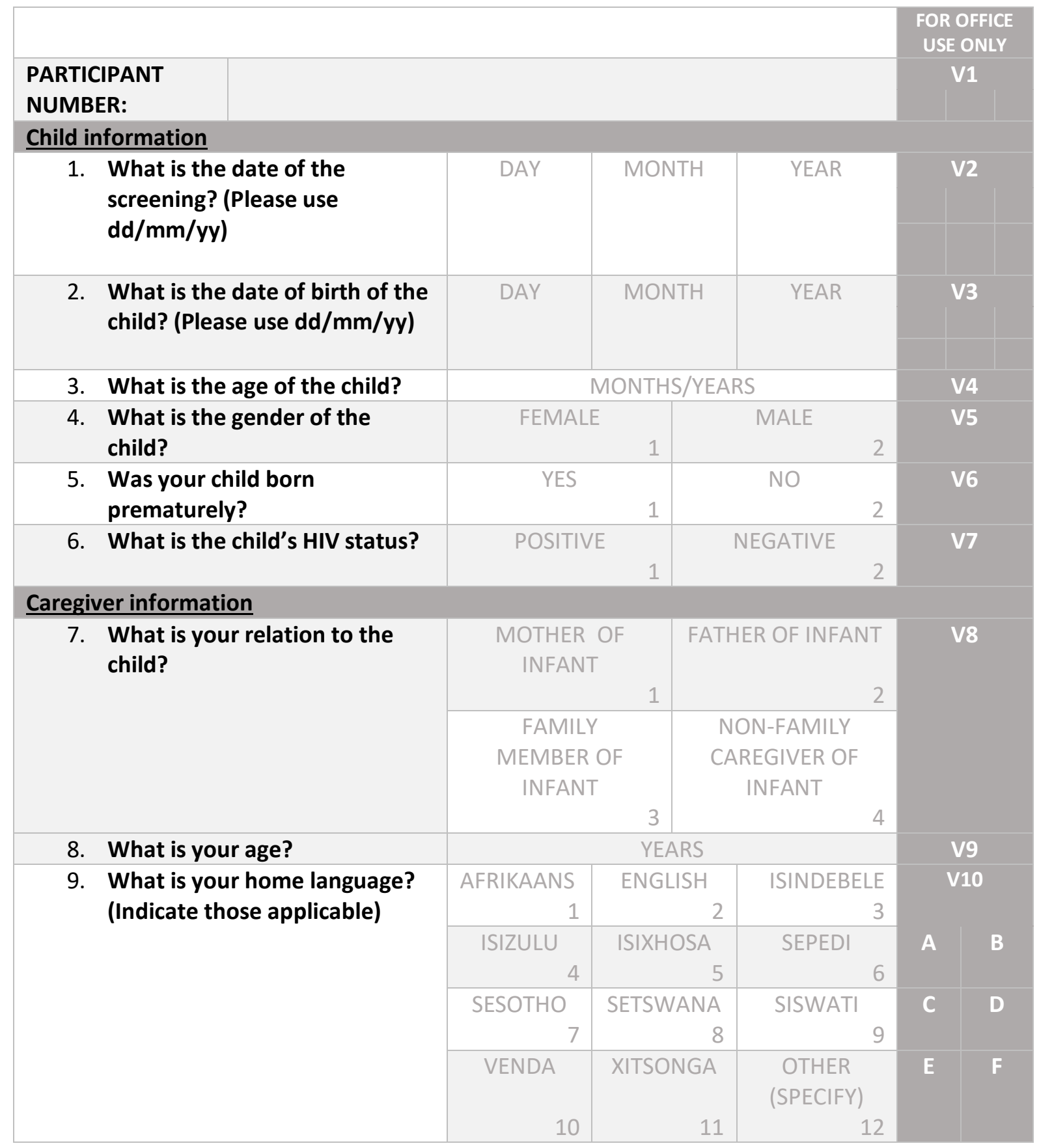




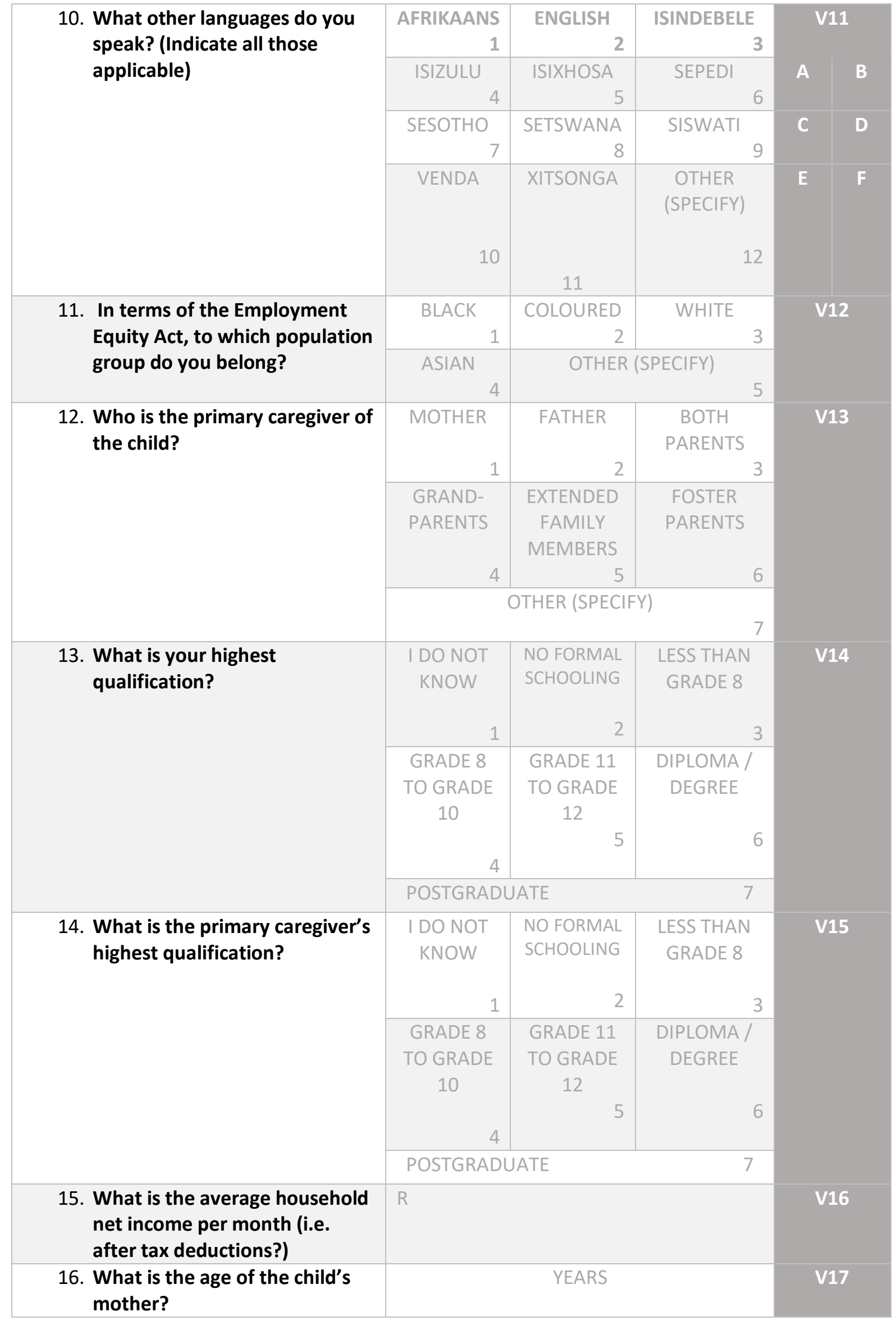




\begin{tabular}{|c|c|c|c|c|c|}
\hline $\begin{array}{l}\text { 17. How many children live in the } \\
\text { household? }\end{array}$ & \multicolumn{2}{|c|}{1} & 2 & $\begin{array}{l}3 \text { OR } \\
\text { MORE }\end{array}$ & V18 \\
\hline \multirow[t]{3}{*}{ 18. What is your marital status? } & \multicolumn{2}{|c|}{ MARRIED } & $\begin{array}{l}\text { NEVER } \\
\text { MARRIED }\end{array}$ & $\begin{array}{l}\text { LIVING } \\
\text { TOGETHER }\end{array}$ & \multirow[t]{3}{*}{ V19 } \\
\hline & \multicolumn{2}{|c|}{ SEPARATED } & WIDOWED & $\begin{array}{l}\text { I DO NOT } \\
\text { KNOW }\end{array}$ & \\
\hline & \multicolumn{4}{|c|}{ DIVORCED } & \\
\hline \multirow[t]{3}{*}{ 19. What is your housing status? } & \multicolumn{2}{|c|}{$\begin{array}{l}\text { OWN MY } \\
\text { HOUSE } \\
\end{array}$} & $\begin{array}{l}\text { OWN MY } \\
\text { FLAT }\end{array}$ & $\begin{array}{l}\text { INFORMAL } \\
\text { HOUSING } \\
3\end{array}$ & \multirow[t]{3}{*}{ V20 } \\
\hline & \multicolumn{2}{|c|}{ I AM RENTING } & $\begin{array}{l}\text { I STAY } \\
\text { WITH } \\
\text { OTHERS }\end{array}$ & OTHER & \\
\hline & $\begin{array}{r}\text { OWN } \\
\text { A }\end{array}$ & $\begin{array}{l}\text { RENTIN } \\
\text { G } \\
\text { B }\end{array}$ & 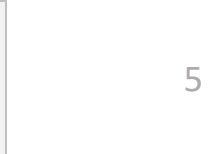 & 6 & \\
\hline \multirow[t]{2}{*}{$\begin{array}{l}\text { 20. At what age did the child start } \\
\text { attending day care/ crèche? }\end{array}$} & \multicolumn{4}{|c|}{ MONTHS/YEARS } & V21 \\
\hline & \multicolumn{4}{|c|}{ NOT ATTENDING DAY CARE } & \\
\hline $\begin{array}{l}\text { 21. How many people are living in } \\
\text { the household? }\end{array}$ & & & & & V22 \\
\hline $\begin{array}{l}\text { 22. Is the primary caregiver } \\
\text { employed? }\end{array}$ & & YES & 1 & NO & V23 \\
\hline \multicolumn{6}{|l|}{ Child's developmental history } \\
\hline \multirow[t]{2}{*}{$\begin{array}{l}\text { 23. Did the child have to stay in } \\
\text { hospital after birth? }\end{array}$} & \multicolumn{2}{|r|}{ YES } & 1 & NO & V24 \\
\hline & \multicolumn{4}{|c|}{ SPECIFY REASONS } & V25 \\
\hline 24. Was the child breastfed? & \multicolumn{2}{|r|}{ YES } & 1 & NO & V26 \\
\hline $\begin{array}{l}\text { 25. When did the child sit for the } \\
\text { first time? }\end{array}$ & \multicolumn{4}{|c|}{ MONTHS } & V27 \\
\hline $\begin{array}{l}\text { 26. When did the child start } \\
\text { walking? }\end{array}$ & \multicolumn{4}{|c|}{ MONTHS } & V28 \\
\hline $\begin{array}{l}\text { 27. When did the child say his } \\
\text { first... }\end{array}$ & \multicolumn{2}{|c|}{$\begin{array}{l}\text { FIRST } \\
\text { WORD }\end{array}$} & $\begin{array}{l}\text { COMBINED } \\
\text { WORDS } \\
2\end{array}$ & SENTENCE & V29 \\
\hline $\begin{array}{l}\text { 28. When did the child start } \\
\text { crawling? }\end{array}$ & \multicolumn{4}{|c|}{ MONTHS } & V30 \\
\hline
\end{tabular}

Thank you for your time and cooperation 
APPENDIX F: COMMUNITY CARE WORKER QUESTIONNAIRE 


\section{Early detection of developmental delays in vulnerable children by community health workers: an mHealth service delivery model}

Below is a list of 9 statements. Please circle the answer that is most appropriate for you as a community health worker.

1- strongly agree

2- agree

3- neutral

4- disagree

5- strongly disagree

1. Instructions for using the PEDS smartphone application were clear and easy to understand.

2. The training I received was adequate for using the PEDS $\begin{array}{lllll}1 & 2 & 3 & 4 & 5\end{array}$ smartphone application.

3. The PEDS smartphone screening was easy to administer. $\quad \begin{array}{lllll}1 & 2 & 3 & 4 & 5\end{array}$

4. The PEDS application was easy to administer in the home $\begin{array}{lllll}1 & 2 & 3 & 4 & 5\end{array}$ setting.

5. The smartphone screening was quick to administer. $\begin{array}{lllll}1 & 2 & 3 & 4 & 5\end{array}$

6. According to me, the caregivers understood the questions $\begin{array}{lllll}1 & 2 & 3 & 4 & 5\end{array}$ that were asked.

7. I trust that the results gotten are true.

$\begin{array}{lllll}1 & 2 & 3 & 4 & 5\end{array}$

8. The caregivers agreed with results of the PEDS screening. $\quad \begin{array}{lllll}1 & 2 & 3 & 4 & 5\end{array}$

9. The screening can have a positive impact in the $\begin{array}{lllll}1 & 2 & 3 & 4 & 5\end{array}$ community.

Any additional comments or recommendations: 